Supporting Information for

\title{
Co(cyclam) Complexes of Triarylamine-acetylide: Structural and Spectroscopic Properties and DFT analysis
}

\author{
Susannah D. Banziger, Adharsh Raghavan, Matthias Zeller and Tong Ren \\ Department of Chemistry, Purdue University, West Lafayette, Indiana 47906, USA
}

\section{Table of Contents:}

1. Crystallographic Details S2-S5

2. Normalized absorption and emission spectra S6

3. Gaussian fit peak analysis for transitions between $20,000 \mathrm{~cm}^{-1}$ and $8,000 \mathrm{~cm}^{-1} \mathrm{~S} 7$

4. ${ }^{1} \mathrm{H}$ NMR Spectra [1]Cl, 2a, 2b, and [3]Cl S8-S9

5. Computational details S10-S23 


\section{Single Crystal X-ray Structure Analyses}

X-ray diffraction data for $[\mathbf{1}] \mathrm{Cl}, \mathbf{2 a}, \mathbf{2 b}$ and $[\mathbf{3}] \mathrm{Cl}$ were obtained on a Bruker Quest diffractometer with a Photon100 CMOS area detector, a fixed chi angle, a sealed tube fine focus X-ray tube, and a single crystal curved graphite incident beam monochromator. Data were collected with $\mathrm{MoK}_{\alpha}$ radiation $(\lambda=0.71073 \AA)$ at $150 \mathrm{~K}$. Data were collected; reflections were indexed and processed using APEX3. The space groups were assigned and the structures were solved by direct methods using XPREP within the SHELXTL suite of programs ${ }^{1}$ and refined using Shelxl and Shelxle.

If not specified otherwise $\mathrm{H}$ atoms attached to carbon, boron and nitrogen atoms as well as hydroxyl hydrogens were positioned geometrically and constrained to ride on their parent atoms. $\mathrm{C}-\mathrm{H}$ bond distances were constrained to $0.95 \AA$ for aromatic and alkene $\mathrm{C}-\mathrm{H}$ and $\mathrm{CH}_{2}$ moieties, and to 0.99 and $0.98 \AA$ for aliphatic $\mathrm{CH}_{2}$ and $\mathrm{CH}_{3}$ moieties, respectively. $\mathrm{N}-\mathrm{H}$ bond distances were constrained to $1.00 \AA$ for pyramidal ( $\mathrm{sp}^{3}$ hybridized) ammonium $\mathrm{NH}^{+}$groups. O-H distances of alcohols were constrained to $0.84 \AA$. Methyl $\mathrm{CH}_{3}$ hydroxyl $\mathrm{H}$ atoms were allowed to rotate but not to tip to best fit the experimental electron density. $\mathrm{U}_{\mathrm{iso}}(\mathrm{H})$ values were set to a multiple of $\mathrm{U}_{\text {eq }}(\mathrm{C})$ with 1.5 for $\mathrm{CH}_{3}$ and $\mathrm{OH}$, and 1.2 for $\mathrm{C}-\mathrm{H}, \mathrm{CH}_{2}$ and $\mathrm{N}-\mathrm{H}$ units, respectively. Additional crystallographic data for $[\mathbf{1}] \mathrm{Cl}, \mathbf{2 a}, \mathbf{2 b}$ and $[\mathbf{3}] \mathrm{Cl}$ are provided below and in Table $\mathrm{S} 1$. CCDC 2013775-2013778 contain the supplementary crystallographic data for compounds [1]Cl, 2a, 2b and [3] Cl respectively. These data can be obtained free of charge from The Cambridge Crystallographic Data Centre. 
Table S1. Crystal data for complexes [1]Cl, 2a, 2b and [3]Cl

\begin{tabular}{|c|c|c|c|c|}
\hline & $\begin{array}{l}{[1] \mathrm{Cl} \cdot \mathrm{THF} \cdot \mathrm{CH}_{3} \mathrm{O}} \\
\mathrm{H}\end{array}$ & 2aTHF & $\mathbf{2 b} \cdot \mathrm{CH}_{3} \mathrm{OH}$ & {$[3] \mathrm{Cl}^{-} \mathrm{CH}_{2} \mathrm{Cl}_{2}$} \\
\hline $\begin{array}{l}\text { Chemical } \\
\text { Formula }\end{array}$ & $\begin{array}{l}\mathrm{C}_{32} \mathrm{H}_{42} \mathrm{ClCoN}_{5} \mathrm{O}_{2} \\
\cdot 0.247\left(\mathrm{C}_{4} \mathrm{H}_{10} \mathrm{O}\right) \cdot \\
1.507\left(\mathrm{CH}_{4} \mathrm{O}\right) \cdot 0.0 \\
5(\mathrm{I}) \cdot 0.95(\mathrm{Cl})\end{array}$ & $\begin{array}{l}\mathrm{C}_{32} \mathrm{H}_{42} \mathrm{Cl}_{3} \mathrm{CoCuN} \\
{ }_{5} \mathrm{O}_{2} \cdot \mathrm{C}_{4} \mathrm{H}_{8} \mathrm{O}\end{array}$ & $\begin{array}{l}\mathrm{C}_{32} \mathrm{H}_{42} \mathrm{AgCoN}_{8} \mathrm{O}_{11} \\
\cdot 1.476\left(\mathrm{CH}_{4} \mathrm{O}\right) \cdot 0.2 \\
09(\mathrm{O})\end{array}$ & $\begin{array}{l}\mathrm{C}_{54} \mathrm{H}_{60} \mathrm{CoN}_{6} \mathrm{O}_{4} \cdot 0 . \\
874\left(\mathrm{CH}_{2} \mathrm{Cl}_{2}\right) \cdot 0.41 \\
5(\mathrm{Br}) \cdot 0.585(\mathrm{Cl})\end{array}$ \\
\hline $\begin{array}{l}\text { Formula } \\
\text { Weight }\end{array}$ & 729.67 & 829.63 & 933.70 & 1044.11 \\
\hline Space Group & $\begin{array}{l}\text { Monoclinic, } \\
P 2_{1} / c\end{array}$ & Triclinic, $P \overline{1}$ & Triclinic, $P \overline{1}$ & Triclinic, $P \overline{1}$ \\
\hline$a, \AA$ & $14.2721(8)$ & $9.3921(8)$ & $10.5925(6)$ & $11.8848(12)$ \\
\hline$b, \AA$ & $24.1352(13)$ & $13.371(2)$ & $11.7280(7)$ & $13.9746(18)$ \\
\hline$c, \AA$ & $10.4474(5)$ & $15.203(2)$ & $16.0527(9)$ & $15.972(3)$ \\
\hline$\alpha, \operatorname{deg}$ & - & $86.645(3)$ & $93.730(2)$ & $104.155(6)$ \\
\hline$\beta, \operatorname{deg}$ & $93.064(2)$ & $77.678(4)$ & $98.254(2)$ & $91.216(6)$ \\
\hline$\gamma, \operatorname{deg}$ & - & $85.353(3)$ & $96.435(2)$ & $91.053(4)$ \\
\hline $\mathrm{V}, \AA^{3}$ & $3593.6(3)$ & $1857.4(4)$ & $1954.4(2)$ & $2570.8(6)$ \\
\hline $\mathrm{Z}$ & 4 & 2 & 2 & 2 \\
\hline $\mathrm{T}, \mathrm{K}$ & 150 & 150 & 150 & 150 \\
\hline$\lambda, \AA$ & 0.71073 & 0.71073 & 0.71073 & 0.71073 \\
\hline $\begin{array}{l}\Delta \rho_{\max }, \Delta \rho_{\min } \\
\left(\mathrm{e} \AA^{-3}\right)\end{array}$ & $0.66,-0.39$ & $0.42,-0.47$ & $1.15,-1.12$ & $0.72,-0.39$ \\
\hline$R$ & 0.046 & 0.026 & 0.041 & 0.044 \\
\hline$R_{w}\left(F^{2}\right)$ & 0.126 & 0.085 & 0.103 & 0.142 \\
\hline
\end{tabular}

\section{Special Refinement Details}

The $\mathrm{O} 4$ methanol is partially substituted by an ether molecule. This affects the hydrogen bonding of the $\mathrm{O} 3$ molecule, extending the disorder to it. The $\mathrm{U}^{\mathrm{ij}}$ components of the ADPs for all disordered atoms within $2.0 \AA$ were restrained to be similar. The distances from oxygen to the first and second carbon on the ether molecule were restrained to be similar to the opposing side. Each C--C distance on ether was also restrained to 1.53(2) A. Further DFIX commands were used for hydrogen bonding considerations. Subject to these conditions, the occupancy for the A and B labelled methanol atoms refined to 0.507(6) and 0.493(6), respectively. The ether molecule is located on an inversion center and its occupancy refines to exactly one half of the B labelled methanol with a value of $0.247(3)$. The chloride anion is partially displaced by an iodide impurity, refining with occupancies of 0.950(2) and 0.050(2), respectively.

\section{Compound 2a}

The tetrahydrofuran solvent molecule was refined as two disordered moieties. The B moiety was restrained to have a similar geometry to the A moiety. All atoms within $2.0 \AA$ were restrained to have similar $\mathrm{U}^{\mathrm{ij}}$ components. Subject to these conditions, the occupancy factors for the A and B moieties refined to $0.729(5)$ and $0.271(5)$, respectively. 


\section{Compound $2 b$}

Disorder of an anisyl ring is correlated with solvent methanol molecule disorder. The anisyl ring (C16-O2B) refined as two separate moieties with the methyl groups pointing in opposite directions. The two moieties were restrained to have similar geometries (SAME command of SHELXL) and $\mathrm{U}^{\mathrm{ij}}$ components of ADPs for disordered atoms closer to each other than $2.0 \AA$ were restrained to be similar. Subject to these conditions the occupancy refined to $0.585(6)$ for C16-O2 and $0.414(4)$ for $\mathrm{C} 16 \mathrm{~B}-\mathrm{O} 2 \mathrm{~B}$. Correlated to the anisyl disorder is disorder of several methanol molecules. They were refined as four disordered moieties, of which the $\mathrm{U}^{\mathrm{ij}}$ components of ADPs were all restrained to be similar for atoms closer to each other than $2.0 \AA$. All methanol O-C bond distances were restrained to $1.45(2) \AA$. O13 is a partially occupied water molecule disordered with one of the anisyl methoxy groups and refined to 0.209(4) occupancy. Hydrogen atoms were omitted for this partially occupied water molecule. For the two methanol moieties closest to the major methoxy moiety the sums of occupancies were restrained to unity. For all other methanol and water moieties full occupancy was not enforced. Positions of methanol hydroxyl $\mathrm{H}$ atoms were initially restrained based on hydrogen bonding considerations (DFIX commands restraining the distance to the acceptor atom). In the final refinement cycles they were set to ride on their carrier oxygen atoms. One of the nitrates directly attached to Ag refined as two disordered moieties and were restrained to be similar. The two moieties were restrained to have similar geometries (SAME command of SHELXL) and $\mathrm{U}^{\mathrm{ij}}$ components of ADPs for disordered atoms closer to each other than 2.0 $\AA$ were restrained to be similar. Subject to these conditions occupancies refined to $0.49(3)$ and $0.51(3)$.

\section{Compound $[3] \mathrm{Cl}$}

The anion site is shared between chloride and bromide. Positions and ADPs of Cl1 and Br1 were constrained to be identical, leading to a refined occupancy ratio of $0.585(2)$ to $0.415(2)$ in favor of chloride. A solvate pocket is occupied by disordered methylene chloride molecules. The moieties were restrained to have similar geometries with similar $\mathrm{C}-\mathrm{Cl}$ distances, and $\mathrm{U}^{\mathrm{ij}}$ components of ADPs were restrained to be similar for atoms closer to each other than $1.7 \AA$. Subject to these conditions the occupancy rates refined to $0.416(7), 0.289(4), 0.079(3)$ and $0.090(6)$. 


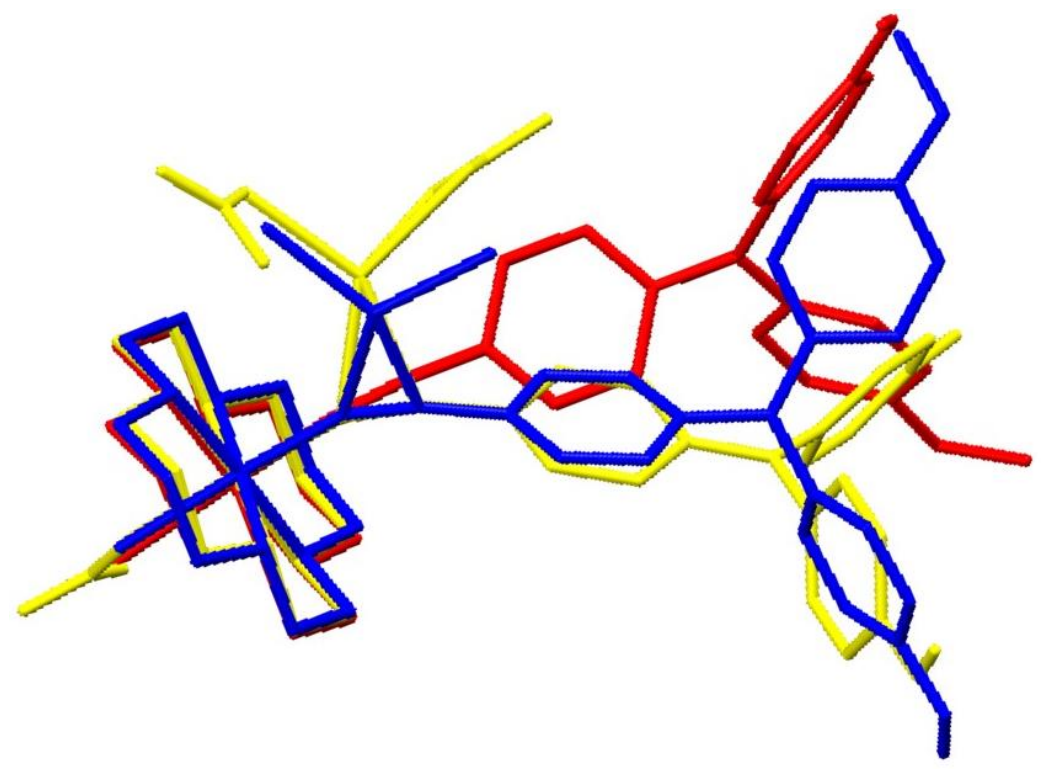

Figure S1. Overlay of compounds [1]Cl (red), $\mathbf{2 a}$ (blue) and $\mathbf{2 b}$ (yellow) showing the effect of $\eta^{2}$ coordination on the Co-C1-C2-C3 dihedral angle. 


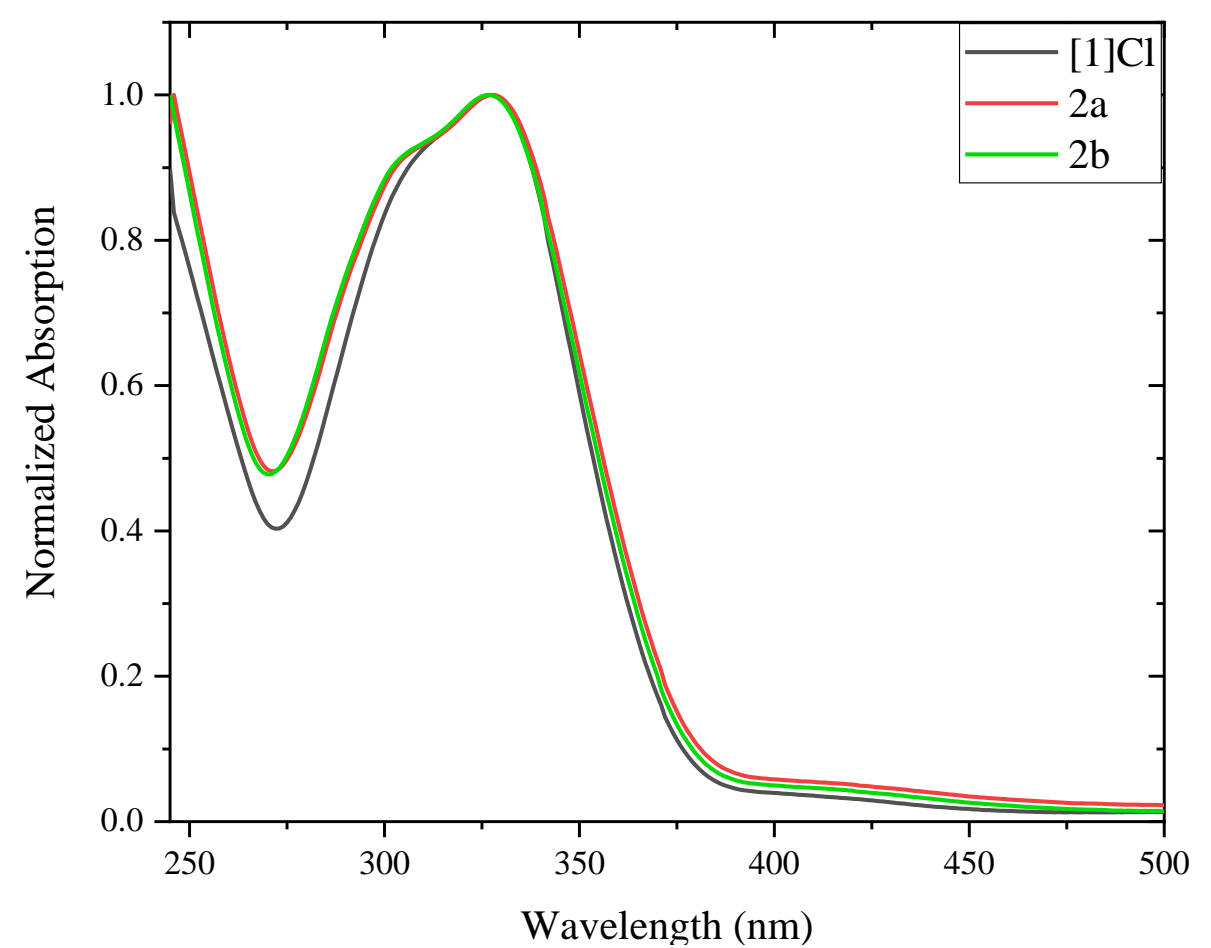

Figure S2. Normalized absorption spectra of [1] Cl, $\mathbf{2 a}$ and $\mathbf{2 b}$ in $\mathrm{CH}_{2} \mathrm{Cl}_{2}$

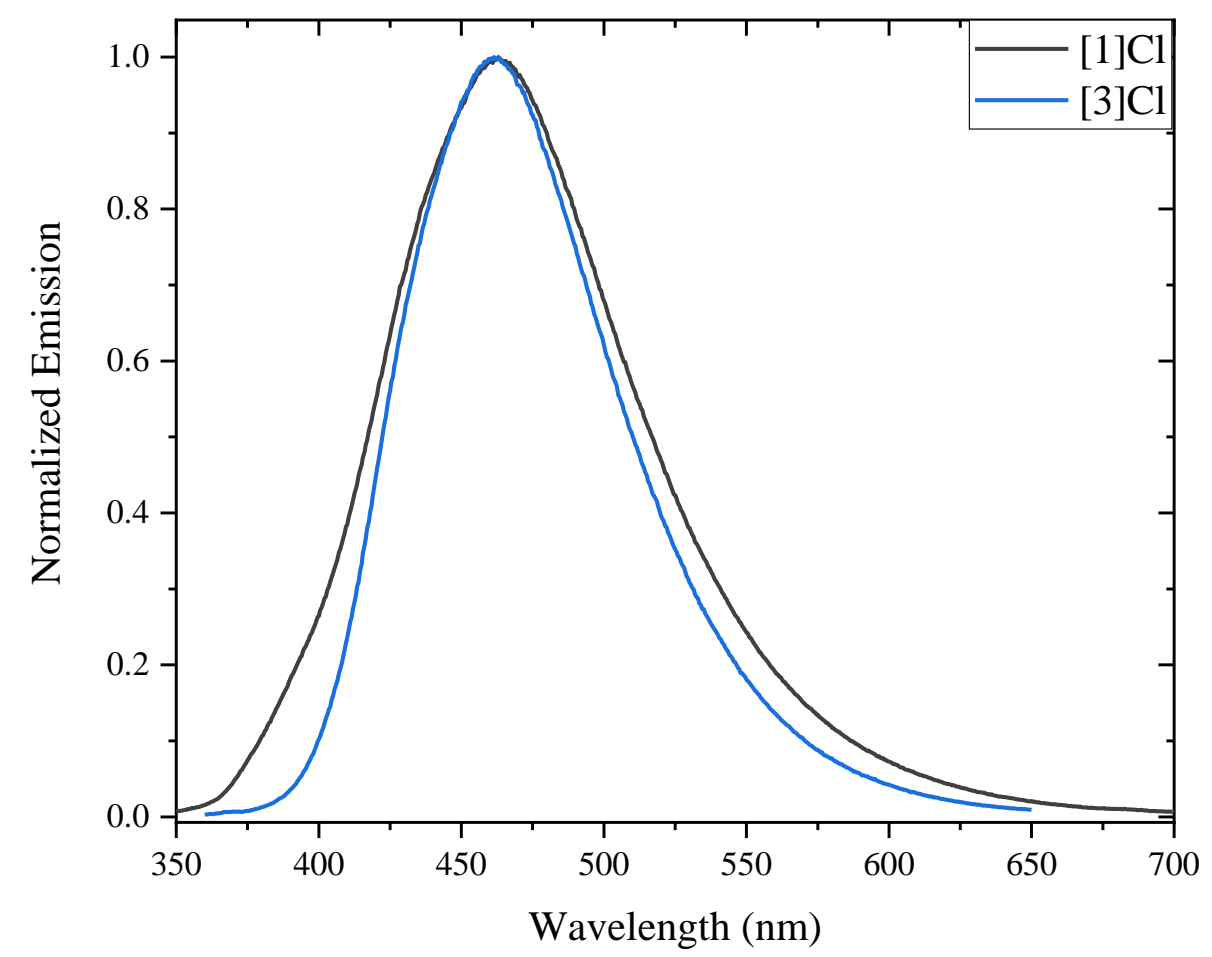

Figure S3. Normalized emission spectra of $[1] \mathrm{Cl}$ and $[3] \mathrm{Cl}$ in $\mathrm{CH}_{2} \mathrm{Cl}_{2}$ at room temperature 
Table S2. Gaussian fit peak analysis for transitions between $20,000 \mathrm{~cm}^{-1}(500 \mathrm{~nm})$ and $8,000 \mathrm{~cm}^{-}$ ${ }^{1}$ (1250 nm). The deconvoluted spectra are shown in Figure S4 and Figure S5.

\begin{tabular}{|c|c|c|c|c|c|}
\hline Compound & Peak & ${ }^{\text {aEOP }}\left(\mathrm{cm}^{-1}\right)$ & ${ }^{a} \varepsilon_{\max }\left(M^{-1} \mathbf{c m}^{-1}\right)$ & ${ }^{b} \Delta v_{1 / 2}\left(\mathrm{~cm}^{-1}\right)$ & $\mathbf{c}^{\mathbf{r}}(\AA)$ \\
\hline$[1] \mathrm{Cl}$ & $\mathbf{A}$ & 14003 & 5928 & 2928 & 8.757 \\
\hline$[1] \mathrm{Cl}$ & $\mathbf{B}$ & 12030 & 6028 & 1655 & 8.757 \\
\hline$[3] \mathrm{Cl}$ & $\mathbf{A}$ & 15158 & 19105 & 2475 & 8.848 \\
\hline$[3] \mathrm{Cl}$ & B & 13277 & 25244 & 2119 & 8.848 \\
\hline$[3] \mathrm{Cl}$ & $\mathbf{C}$ & 11273 & 19105 & 1499 & 8.848 \\
\hline
\end{tabular}

${ }^{a}$ Measured by spectroelectrochemical oxidation. ${ }^{b}$ Determined from deconvoluted spectral analysis $\left(\Delta v_{1 / 2}=\mathrm{fwhm}\right)$. ${ }^{\mathrm{c}}$ Determined based on the geometric distance between the $\mathrm{Co}^{\mathrm{III}}$ metal center and the nitrogen atom of the TPA group in the collected crystal structures. See Figures S4 and S5 for specific assignment.

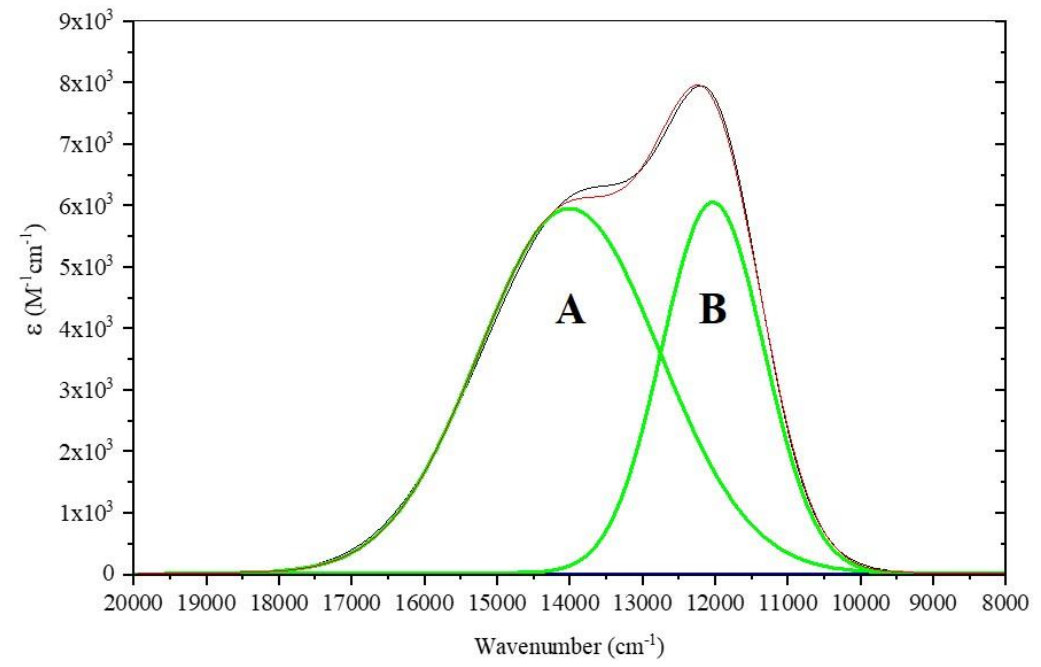

Figure S4. Deconvoluted spectra of the oxidation product from holding compound [1]Cl at 0.88 $\mathrm{V}$ in a MeCN solution containing $0.1 \mathrm{M} n-\mathrm{Bu}_{4} \mathrm{NPF}_{6}$.

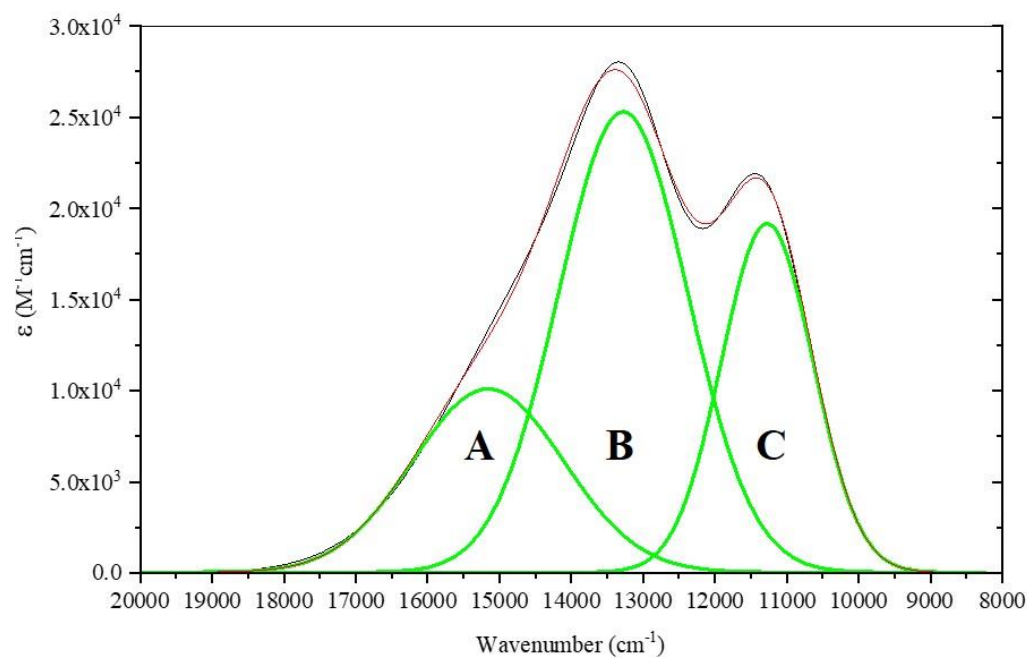

Figure S5. Deconvoluted spectra of the oxidation product formed from holding compound [3]Cl at $0.88 \mathrm{~V}$ in a $\mathrm{MeCN}$ solution containing $0.1 \mathrm{M} n-\mathrm{Bu}_{4} \mathrm{NPF}_{6}$. 


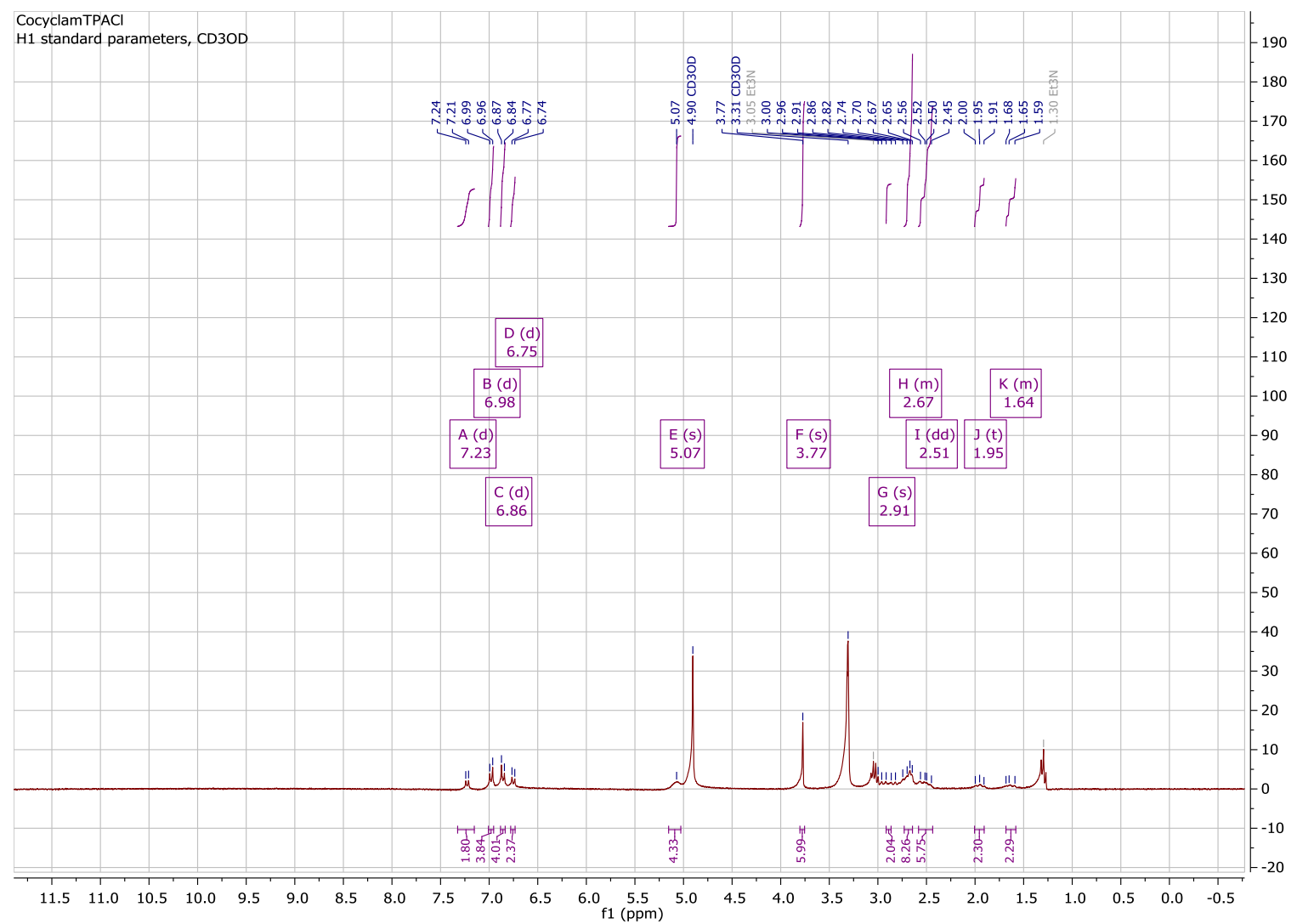

Figure S6. ${ }^{1} \mathrm{H} \mathrm{NMR}$ of $[1] \mathrm{Cl}\left[\mathrm{Co}(\right.$ cyclam $\left.)\left(\mathrm{C}_{2} \mathrm{TPA}\right) \mathrm{Cl}\right] \mathrm{Cl}$ in $\mathrm{CD}_{3} \mathrm{OD}$

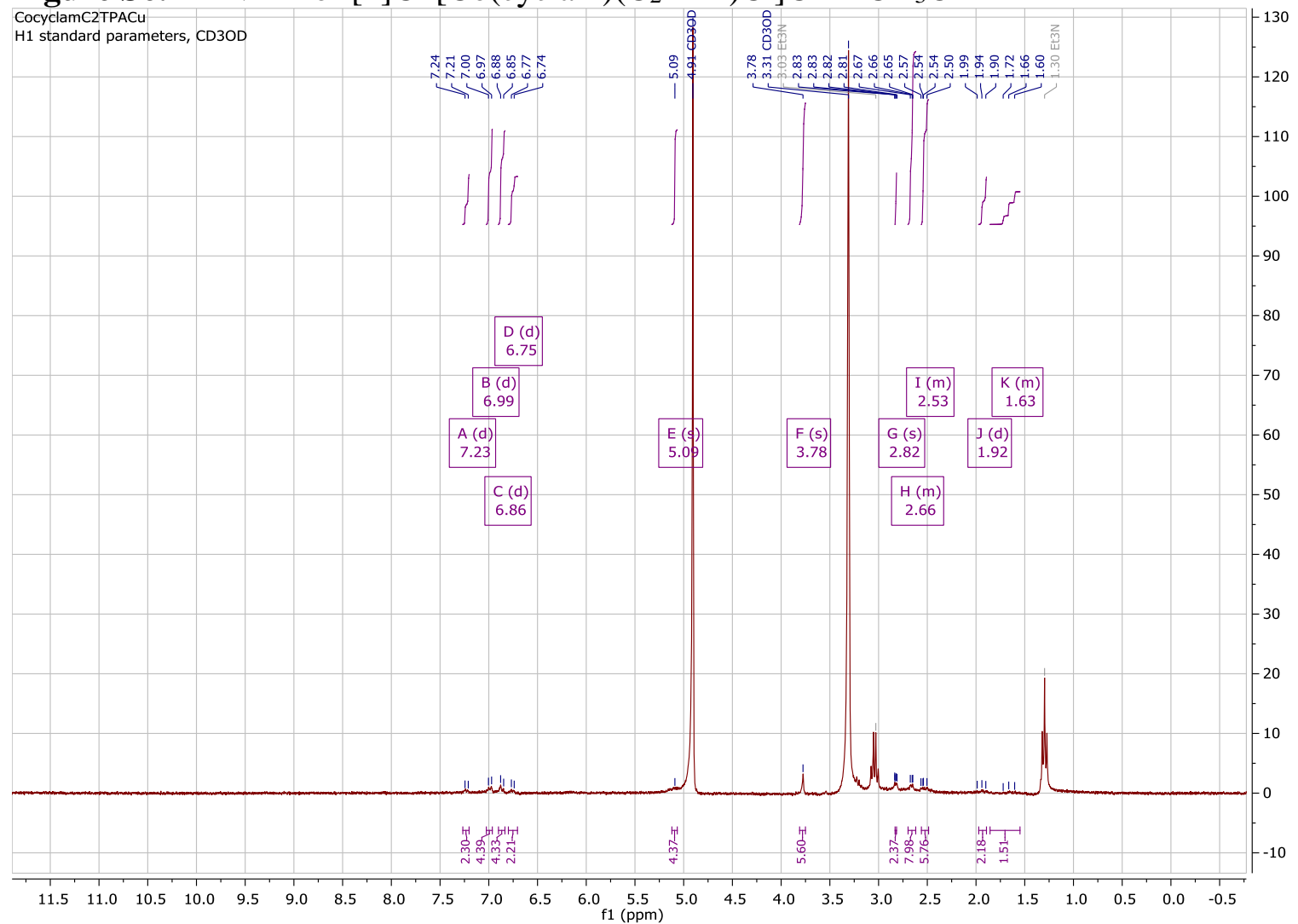

Figure S7. ${ }^{1} \mathrm{H} \mathrm{NMR}$ of $\mathbf{2 a}\left[\mathrm{Co}(\right.$ cyclam $\left.)\left(\mathrm{C}_{2} \mathrm{TPA}-\eta^{2}-\mathrm{CuCl}_{2}\right) \mathrm{Cl}\right]$ in $\mathrm{CD}_{3} \mathrm{OD}$ 


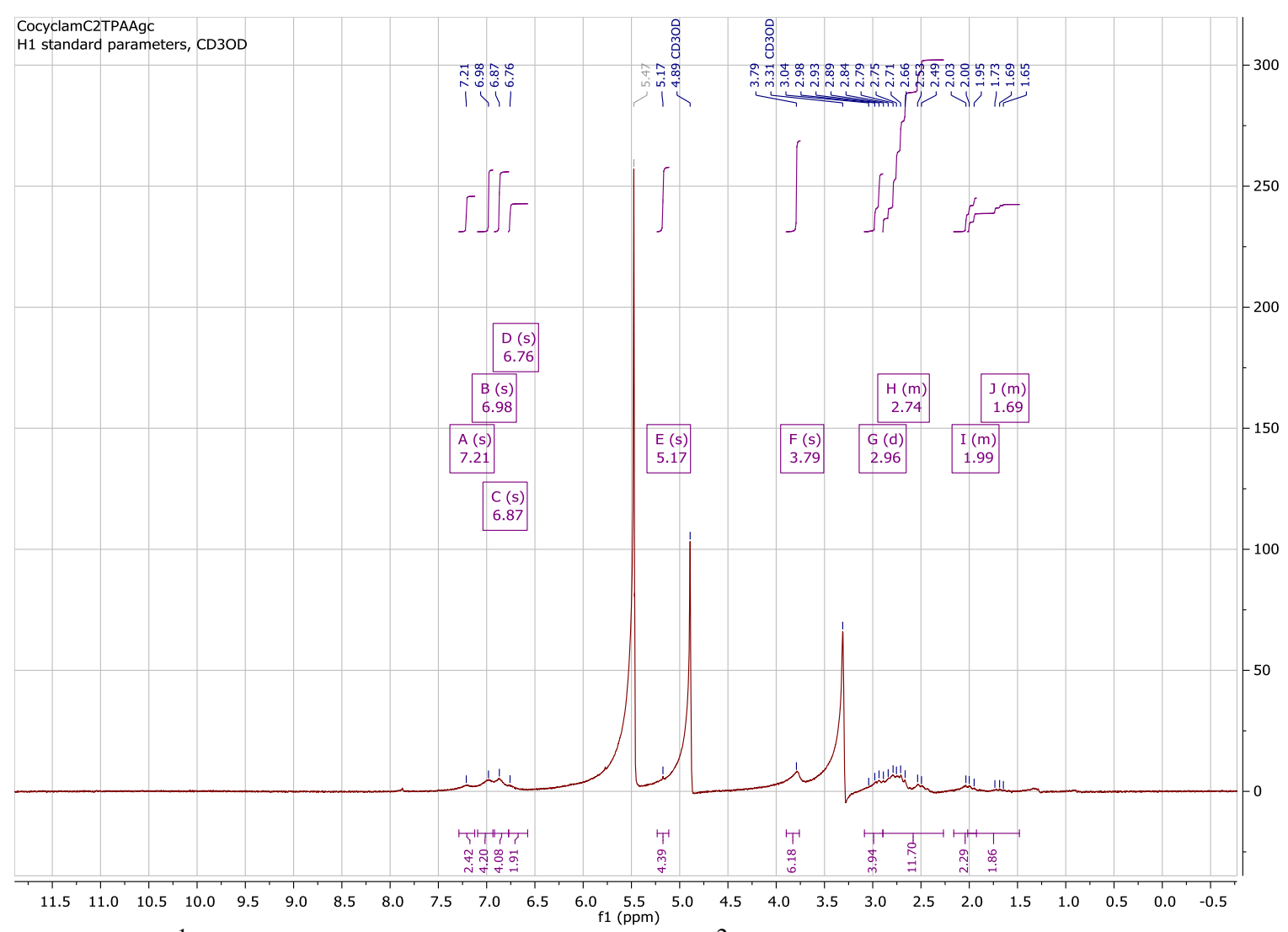

Figure S8. ${ }^{1} \mathrm{H}$ NMR of $\mathbf{2 b}\left[\mathrm{Co}(\right.$ cyclam $\left.)\left(\mathrm{C}_{2} \mathrm{TPA}-\eta^{2}-\mathrm{Ag}\left(\mathrm{NO}_{3}\right)_{2}\right)\left(\mathrm{NO}_{3}\right)\right]$ in $\mathrm{CD}_{3} \mathrm{OD}$ CocyclamTPA2CdCI3b
H1 standard parameters, $\mathrm{CDCl} 3$

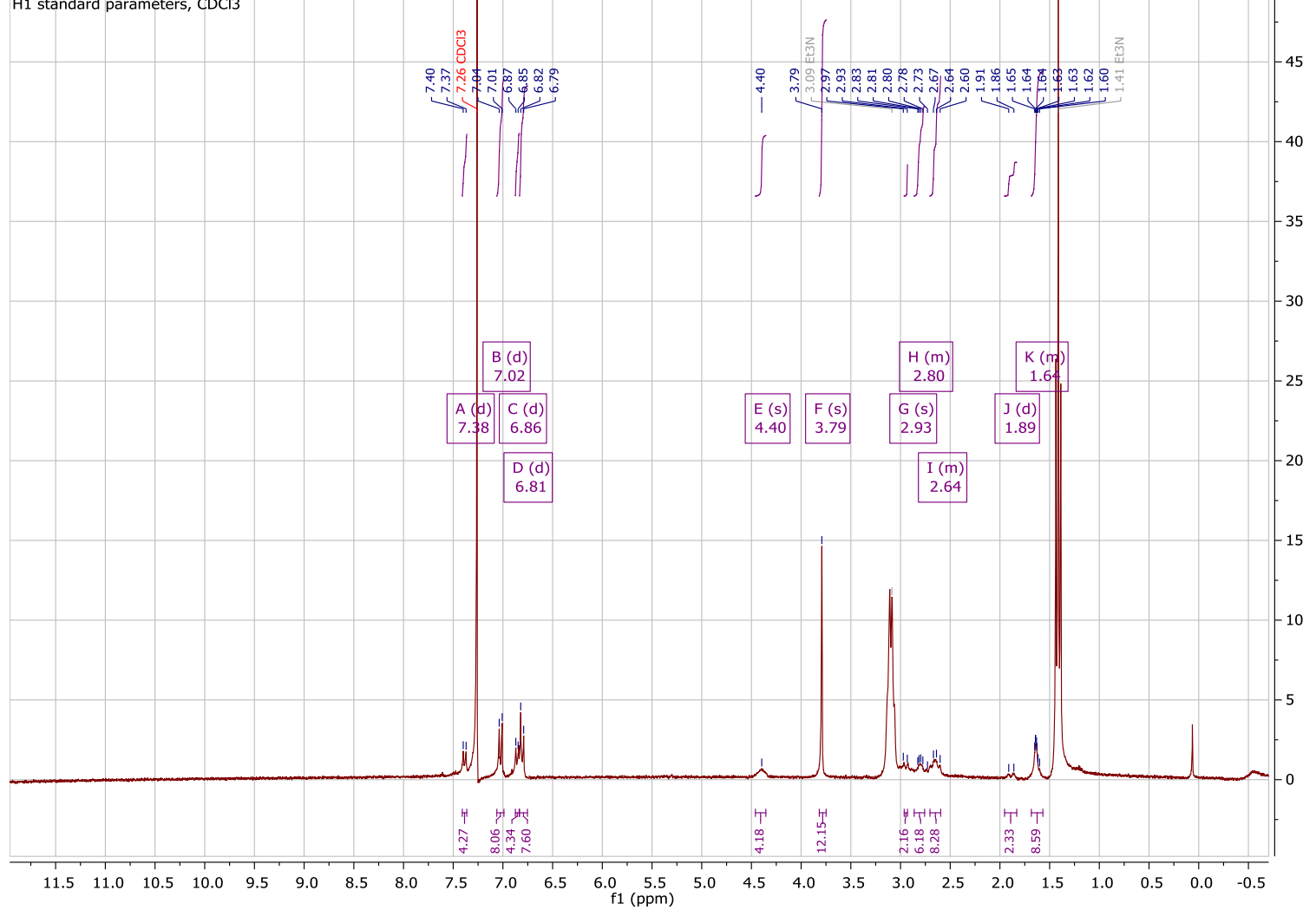

Figure S9. ${ }^{1} \mathrm{H}$ NMR of $[3] \mathrm{Cl}\left[\mathrm{Co}(\right.$ cyclam $\left.)\left(\mathrm{C}_{2} \mathrm{TPA}\right)_{2}\right] \mathrm{Cl}$ in $\mathrm{CDCl}_{3}$ 


\section{Computational details}

All DFT calculations were performed using Gaussian16 (rev. A.03) program. ${ }^{2}$ Both ground and excited state calculations were performed at the same level of theory. While the functionals B3LYP ${ }^{3-6}$ BP86, ${ }^{5}$ CAM-B3LYP, ${ }^{7}$ M06, ${ }^{8}$ wB97X ${ }^{9}$ and M06HF. ${ }^{10}$ All gave ground-state metrical parameters close to experimentally obtained ones for $[\mathbf{1}]^{+}$and $[\mathbf{3}]^{+}$, excited state calculations were more or less accurate only in the case of M06. Hence, all further calculations were carried out using this functional.

The def2-tzvp ${ }^{11}$ basis set was used for Co and 6-31G(d,p $)^{12,13}$ for all other atoms. Additionally, a solvation model (polarizable continuum model ${ }^{14,15}$ for acetonitrile) and Grimme's empirical dispersion correction parameters were employed for all calculations. ${ }^{16}$ For all ground-state calculations, minima were ensured through vibrational frequency analyses.

The M06-HF functional, which employs 100\% HF exchange performed very poorly. Both B3LYP and the long-range-corrected functional CAM-B3LYP, which has been utilized previously for Fc-TPA systems ${ }^{17}$ also performed poorly. The M06 functional, which employs $27 \% \mathrm{HF}$ exchange, was found to the be the most accurate for these systems. The Tamm-Dancoff approximation (TDA) was used for all TD-DFT calculations since it is known to give results that are close to, or sometimes even better than full linear-response TD-DFT. ${ }^{18}$ In order to better visualize the qualitative nature of the electronic transitions, natural transition orbitals (NTOs) were computed using the method developed by Martin. ${ }^{19}$

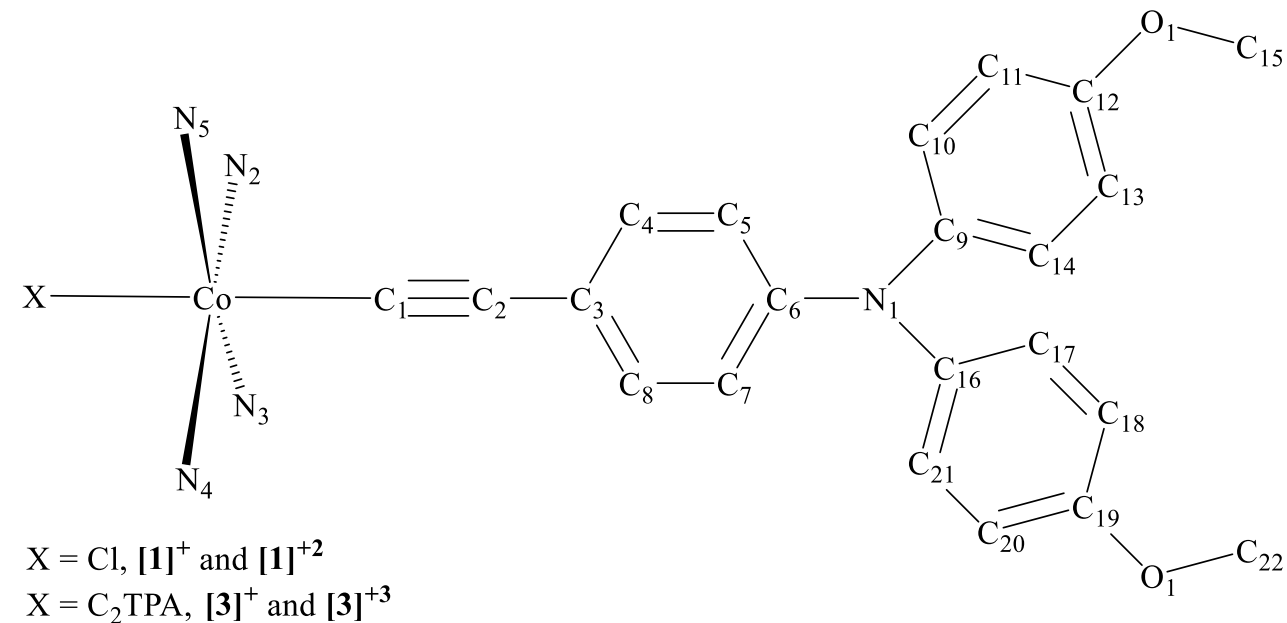

Chart S1. Schematic legend for Table S3

Table S3. Comparison of experimental and DFT-optimized metrical parameters ${ }^{a}$

\begin{tabular}{|c|c|c|c|c|c|c|}
\hline & {$[\mathbf{1}]^{+}$, expt } & {$[\mathbf{1}]^{+}$} & {$[\mathbf{1}]^{+2}$} & {$[3]^{+}$, expt } & {$[3]^{+}$} & {$[3]^{+3}$} \\
\hline $\mathrm{Co}-\mathrm{Cl}$ & $2.3401(7)$ & 2.33104 & 2.32111 & - & - & - \\
\hline $\begin{array}{c}\text { Co- } \mathrm{N}_{\text {cyclam }} \\
\text { (ave) }\end{array}$ & $1.975[1]$ & 1.99042 & 1.99095 & $1.990[1]$ & 1.99457 & 1.99598 \\
\hline $\mathrm{Co}-\mathrm{C} 1$ & $1.879(3)$ & 1.88642 & 1.88356 & $1.945(2)$ & 1.93688 & 1.92984 \\
\hline $\mathrm{C} 1-\mathrm{C} 2$ & $1.205(4)$ & 1.22539 & 1.22610 & $1.203(3)$ & 1.22859 & 1.22921 \\
\hline
\end{tabular}




\begin{tabular}{|c|c|c|c|c|c|c|}
\hline C2-C3 & $1.434(4)$ & 1.42671 & 1.41871 & $1.446(3)$ & 1.42731 & 1.41769 \\
\hline C3-C4 & $1.395(4)$ & 1.40315 & 1.40743 & $1.402(3)$ & 1.40465 & 1.40959 \\
\hline C4-C5 & $1.382(4)$ & 1.38460 & 1.37973 & $1.388(3)$ & 1.38435 & 1.37870 \\
\hline C5-C6 & $1.393(4)$ & 1.40384 & 1.40509 & $1.407(3)$ & 1.40370 & 1.40585 \\
\hline C6-C7 & $1.388(4)$ & 1.40394 & 1.40527 & $1.406(3)$ & 1.40305 & 1.40553 \\
\hline C7-C8 & $1.387(4)$ & 1.38410 & 1.37904 & $1.388(3)$ & 1.38527 & 1.37912 \\
\hline C8-C3 & $1.404(4)$ & 1.40406 & 1.40888 & $1.405(3)$ & 1.40347 & 1.40866 \\
\hline N1-C6 & $1.431(3)$ & 1.40152 & 1.40414 & $1.410(3)$ & 1.40290 & 1.40309 \\
\hline N1-C9 & $1.420(4)$ & 1.42012 & 1.40276 & $1.434(3)$ & 1.41988 & 1.40319 \\
\hline C9-C10 & $1.391(4)$ & 1.39371 & 1.40353 & $1.381(4)$ & 1.39374 & 1.40315 \\
\hline C10-C11 & $1.376(4)$ & 1.39226 & 1.38181 & $1.401(4)$ & 1.39239 & 1.38197 \\
\hline C11-C12 & $1.388(5)$ & 1.39572 & 1.40339 & $1.365(4)$ & 1.39574 & 1.40310 \\
\hline C12-C13 & $1.386(4)$ & 1.39936 & 1.40696 & $1.398(4)$ & 1.39933 & 1.40683 \\
\hline C13-C14 & $1.388(4)$ & 1.38358 & 1.37430 & $1.385(4)$ & 1.38359 & 1.37459 \\
\hline C14-C9 & $1.384(4)$ & 1.39991 & 1.40859 & $1.383(4)$ & 1.40004 & 1.40834 \\
\hline C12-O1 & $1.375(4)$ & 1.35625 & 1.33638 & $1.371(3)$ & 1.35653 & 1.33688 \\
\hline O1-C15 & $1.417(5)$ & 1.41181 & 1.42085 & $1.435(4)$ & 1.41176 & 1.42059 \\
\hline Co-C1-C2 & $172.6(2)$ & 175.09752 & 176.6865 & $175.8(2)$ & 174.77895 & 176.18823 \\
\hline C1-C2-C3 & $171.6(3)$ & 178.37572 & 178.39047 & $177.5(3)$ & 177.80433 & 177.59653 \\
\hline
\end{tabular}

${ }^{a}$ there is a mirror symmetry along $\mathrm{Co}-\mathrm{N}_{1}$ vector and bisecting the acetylene bearing phenyl group. Atoms related by this symmetry are omitted. 


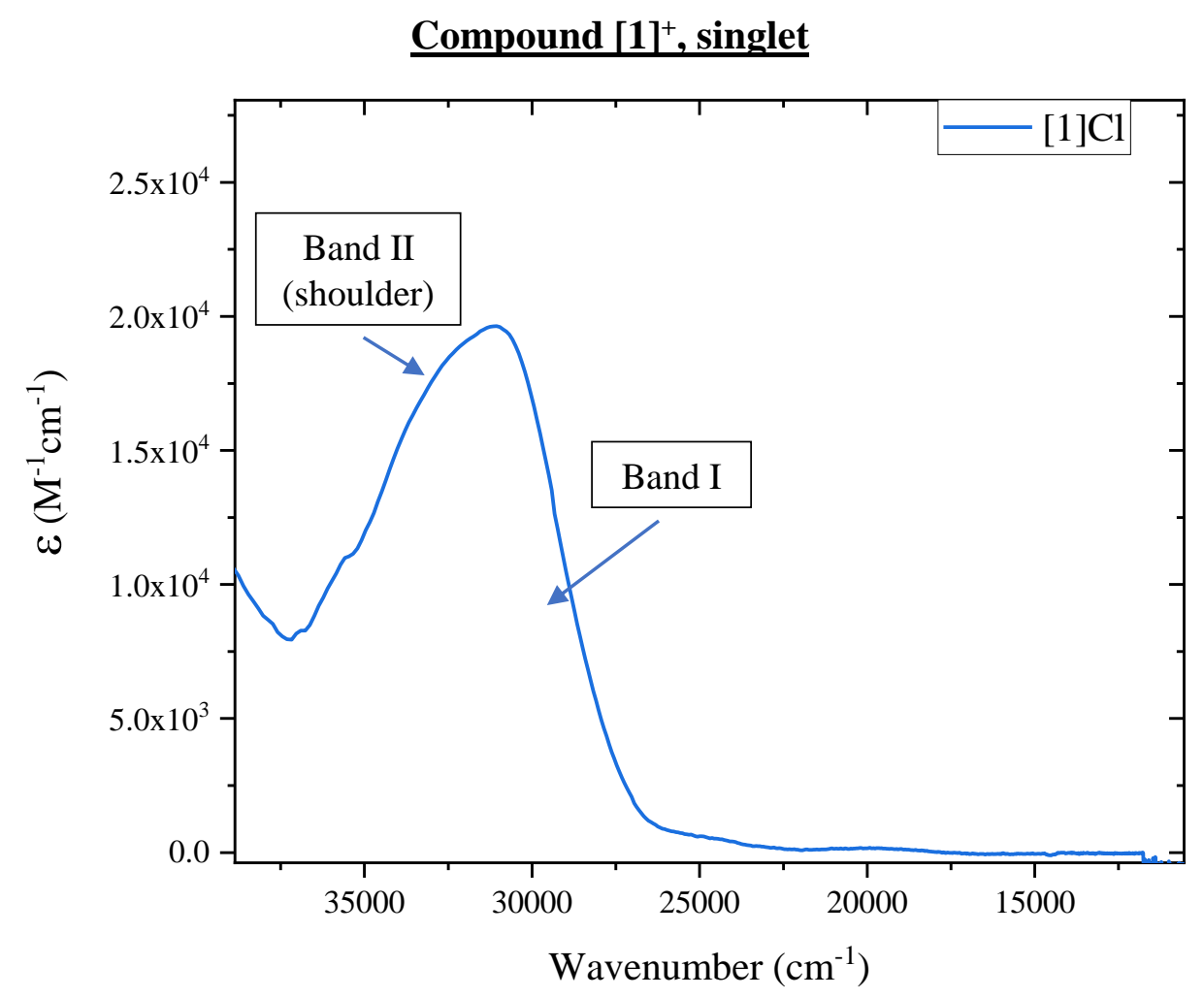

Figure S10. Experimental UV-Vis spectrum of [1] Cl in $\mathrm{MeCN}$. The major peak (and its associated shoulder) in the spectrum can be split into two bands: I and II (shoulder).

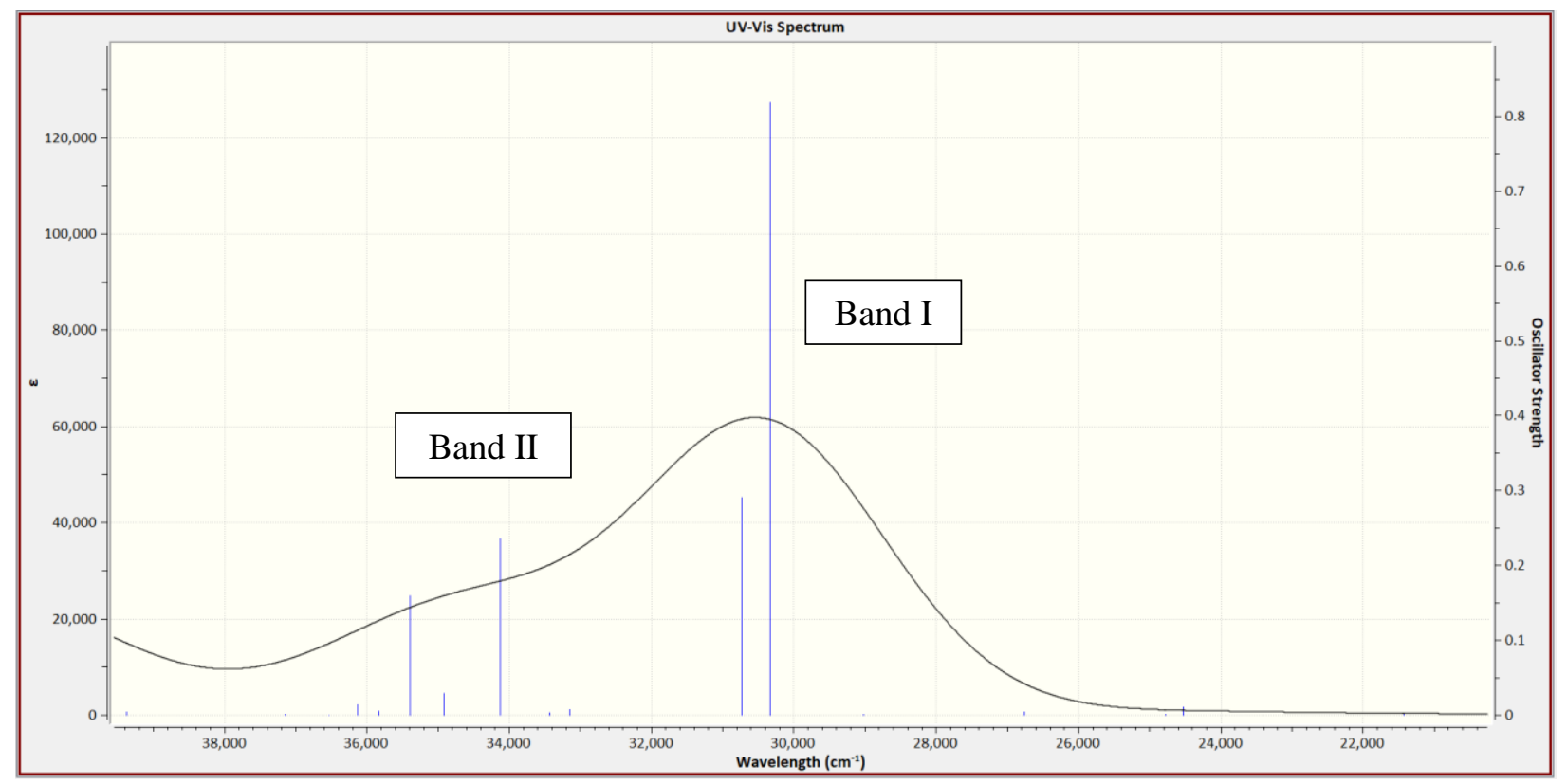

Figure S11. TD-DFT-simulated UV-Vis spectrum of $[1]^{+}$

While there are noticeable quantitative differences between experiment and theory (molar absorptivities, especially), there is qualitative agreement on the existence of two major bands, each consisting of very few closely spaced transitions. TD-DFT over-estimates the energies of 
the transitions associated with 'Band II'. Bands I and II both consist of $\pi \rightarrow \pi^{*}$ transitions involving either the TPA moiety or the $\mathrm{C} \equiv \mathrm{C}$-TPA moiety. The associated excited states and Natural Transition Orbitals (NTOs) are:

Table S4. NTOs computed for the excited states of $[1]^{+}$. Transitions are noted in the direction NTO1 (hole) $\rightarrow$ NTO2 (electron). |isovalue $=0.025$.

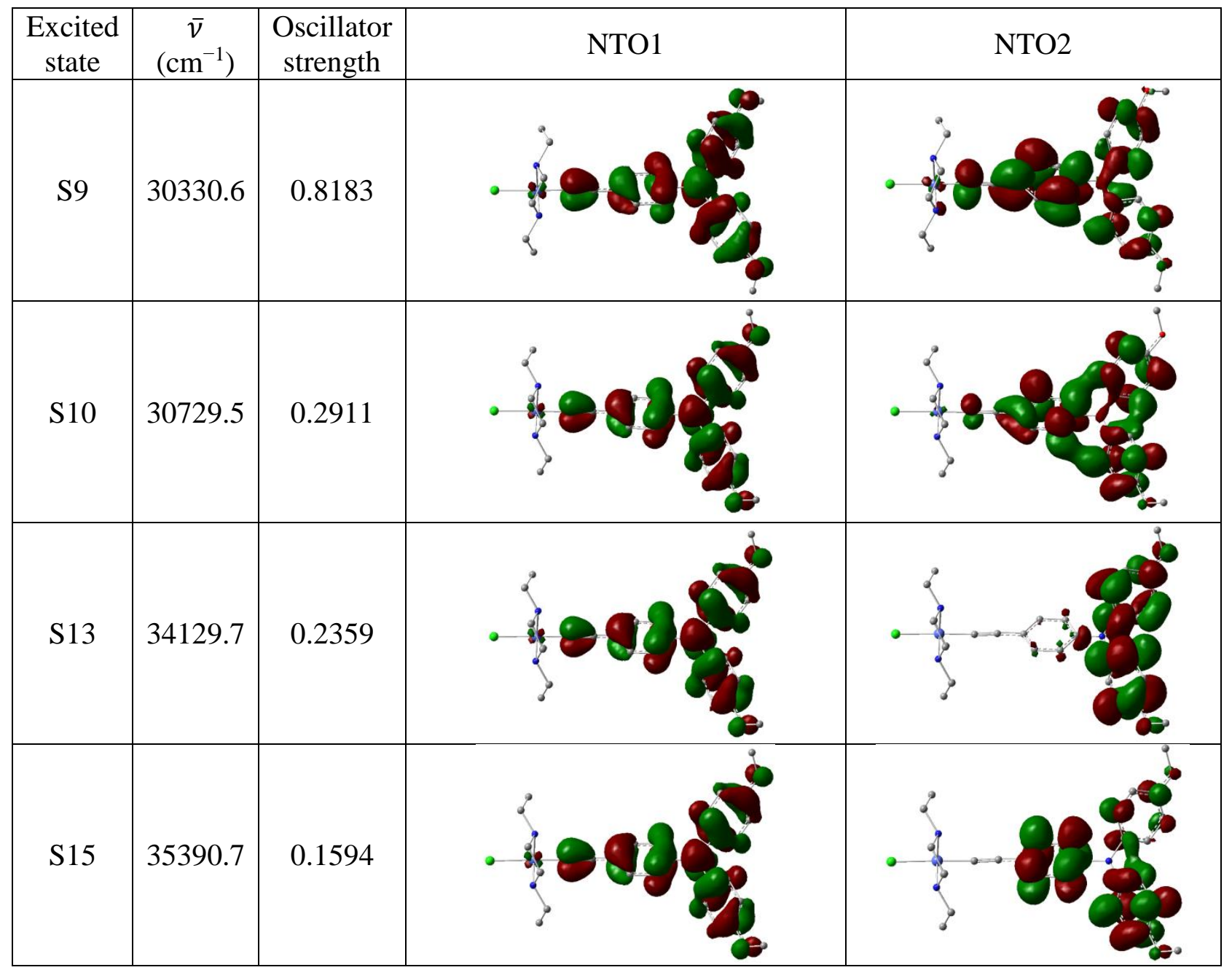




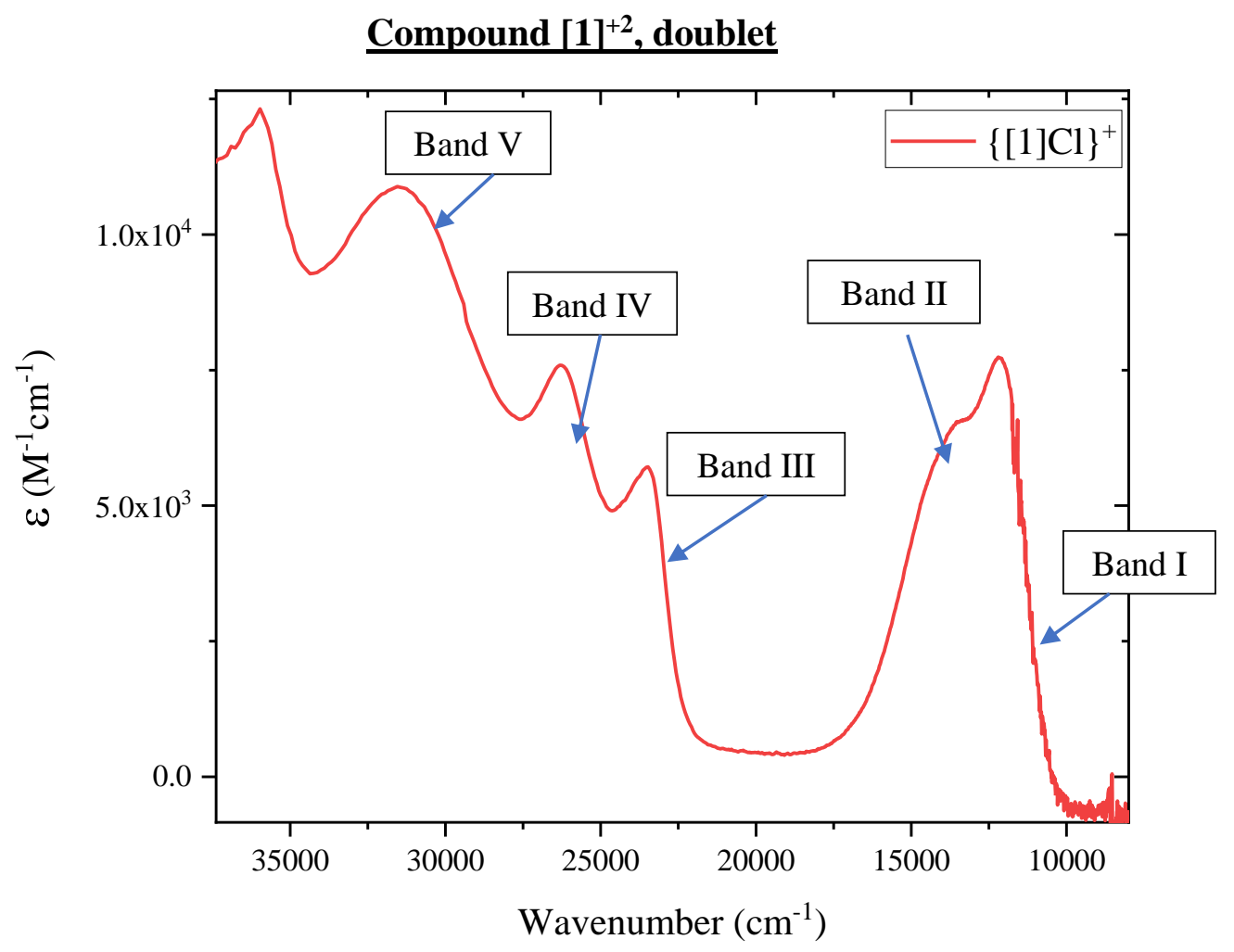

Figure S12. Experimental UV-Vis spectrum of $\{[1] \mathrm{Cl}\}^{+}$in $\mathrm{MeCN}$, obtained by spectroelectrochemistry.

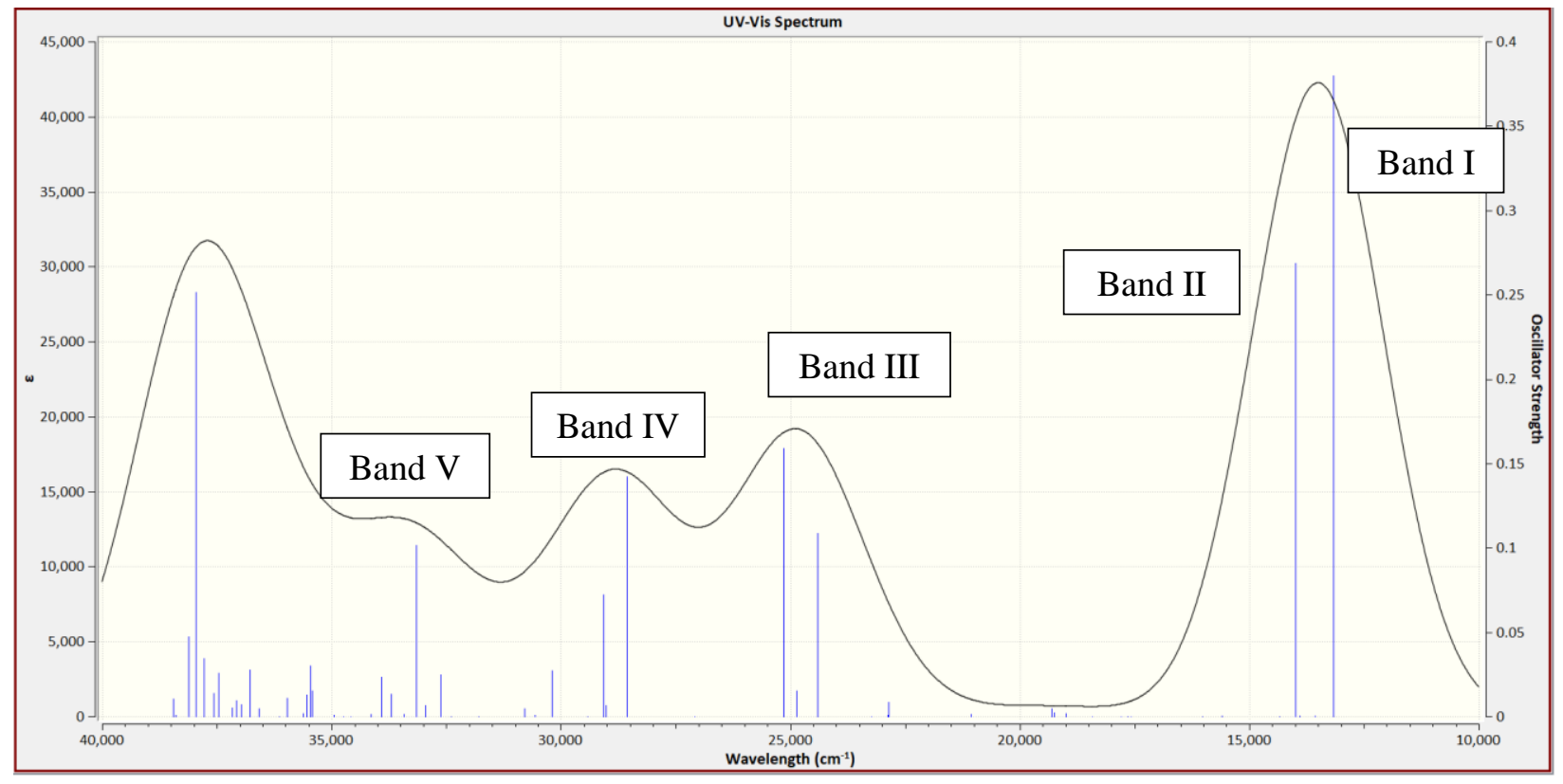

Figure S13. TD-DFT simulated UV-Vis spectrum of $[1]^{+2}$. 
Table S5. NTOs computed for the excited states of $[\mathbf{1}]^{+2}$. Transitions are noted as NTO1 (hole) $\rightarrow$ NTO2 (electron). |isovalue $\mid=0.025$.

\begin{tabular}{|c|c|c|c|c|}
\hline $\begin{array}{c}\text { Excited } \\
\text { state }\end{array}$ & $\begin{array}{c}\bar{v} \\
\left(\mathrm{~cm}^{-1}\right)\end{array}$ & $\begin{array}{l}\text { Oscillator } \\
\text { strength }\end{array}$ & NTO1 & NTO2 \\
\hline D1 & 13164.8 & 0.3797 & & \\
\hline D4 & 13987.6 & 0.2686 & & \\
\hline $\begin{array}{l}\text { D19 } \\
\text { major }\end{array}$ & 24417 & 0.1087 & & \\
\hline $\begin{array}{l}\text { D19 } \\
\text { minor }\end{array}$ & 24417 & 0.1087 & & \\
\hline $\begin{array}{l}\text { D21 } \\
\text { major }\end{array}$ & 25145.2 & 0.159 & & \\
\hline $\begin{array}{l}\text { D21 } \\
\text { major }\end{array}$ & 25145.2 & 0.159 & & \\
\hline
\end{tabular}




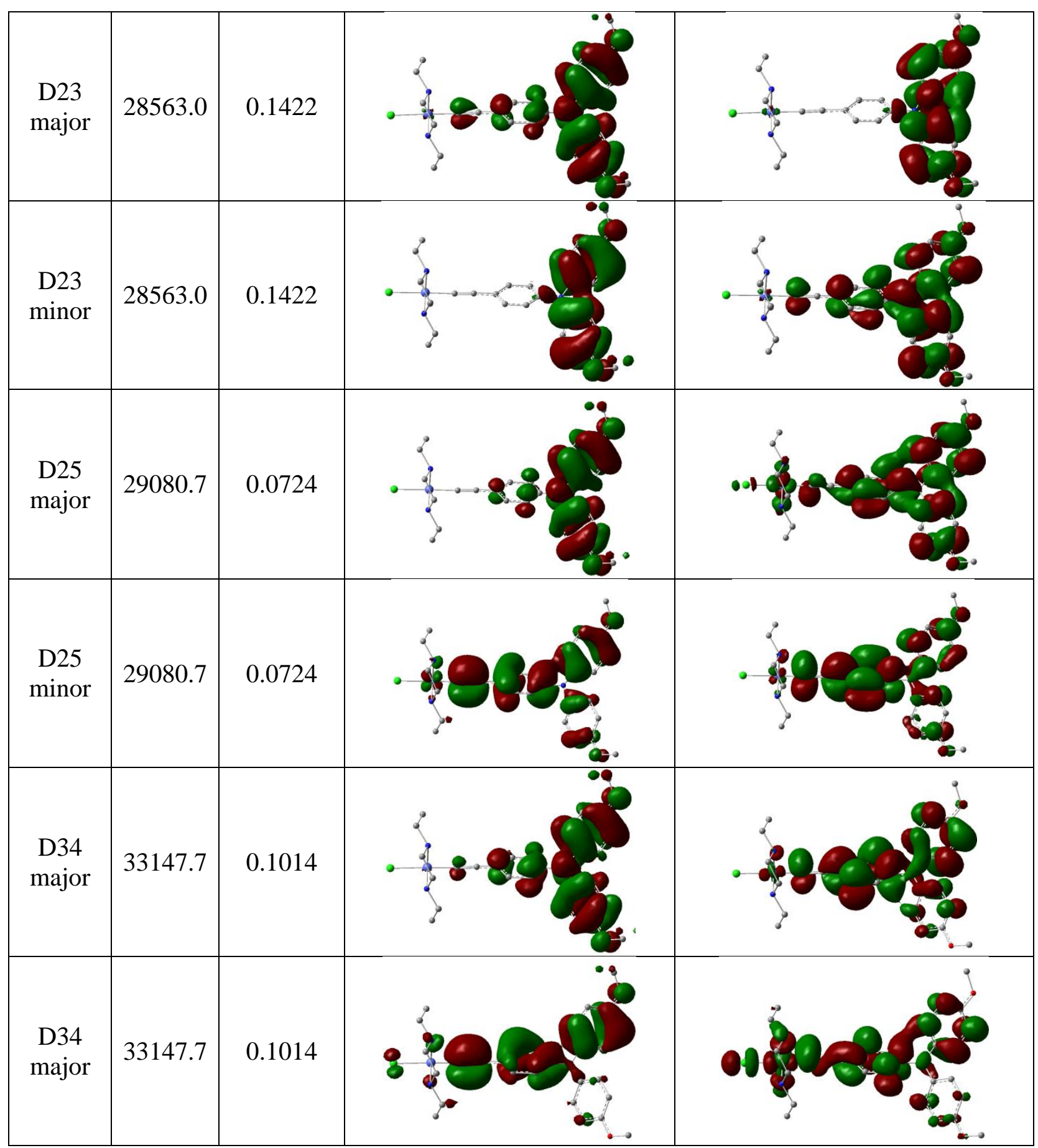




\section{Compound $[3]^{+}$, singlet}

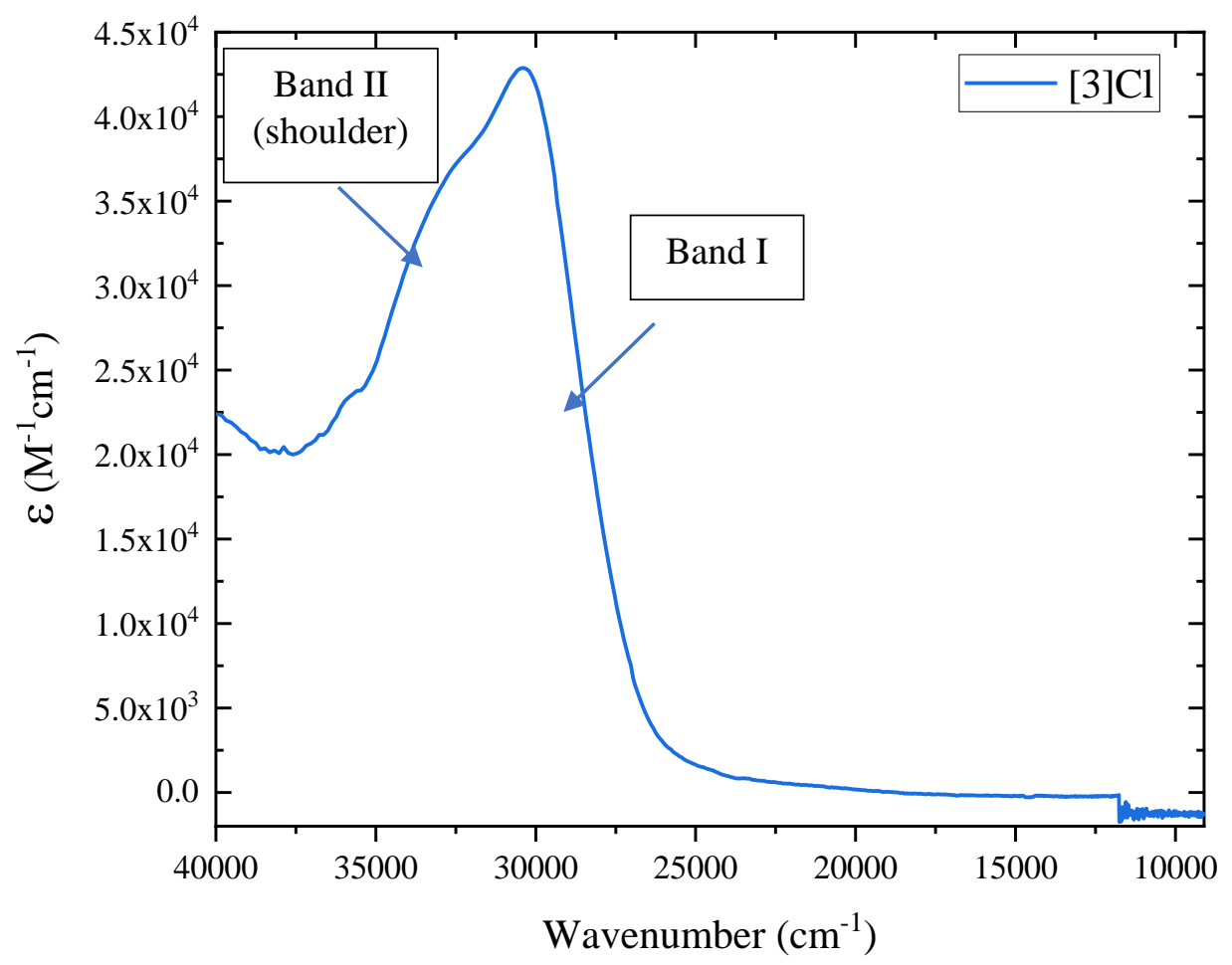

Figure S14. Experimental UV-Vis spectrum of $[3] \mathrm{Cl}$ in $\mathrm{MeCN}$.

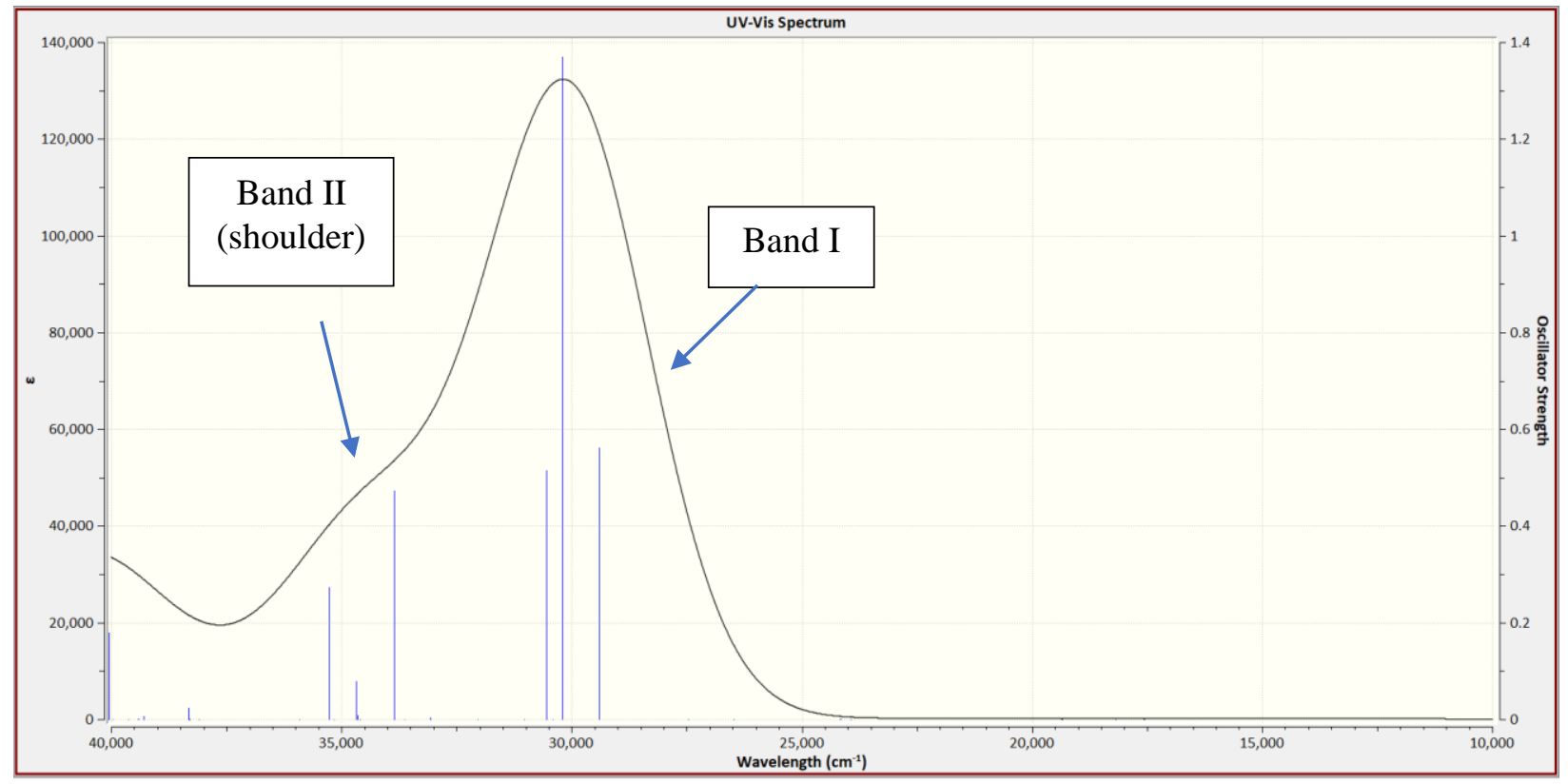

Figure S15. TD-DFT simulated UV-Vis spectrum of [3] $]^{+}$

The same issues with the simulation of the UV-Vis spectrum of compound $[\mathbf{1}]^{+}$are present with that of compound $[3]^{+}$. TD-DFT over-estimates the energies of the transitions associated with 'Band II'. 
Table S6. NTOs computed for the excited states of $[3]^{+}$. Transitions are noted as NTO1 (hole) $\rightarrow$ NTO2 (electron). |isovalue $\mid=0.025$.

\begin{tabular}{|c|c|c|c|c|}
\hline $\begin{array}{l}\text { Excite } \\
\text { d state }\end{array}$ & $\begin{array}{c}\bar{v} \\
\left(\mathrm{~cm}^{-1}\right)\end{array}$ & $\begin{array}{l}\text { Oscillator } \\
\text { strength }\end{array}$ & NTO1 & NTO2 \\
\hline S8 & $\begin{array}{c}29414 . \\
4\end{array}$ & 0.562 & & \\
\hline $\begin{array}{c}\text { S9 } \\
\text { major }\end{array}$ & $\begin{array}{c}30198 . \\
7\end{array}$ & 1.3693 & & \\
\hline $\begin{array}{l}\text { S9 } \\
\text { major }\end{array}$ & $\begin{array}{c}30198 . \\
7\end{array}$ & 1.3693 & & \\
\hline $\begin{array}{l}\text { S11 } \\
\text { major }\end{array}$ & $\begin{array}{c}30543 . \\
7\end{array}$ & 0.5154 & & \\
\hline $\begin{array}{l}\mathrm{S} 11 \\
\text { major }\end{array}$ & $\begin{array}{c}30543 . \\
7\end{array}$ & 0.5154 & & \\
\hline $\begin{array}{c}\text { S17 } \\
\text { Major }\end{array}$ & $\begin{array}{c}33865 . \\
0\end{array}$ & 0.4733 & & \\
\hline $\begin{array}{l}\mathrm{S} 17 \\
\text { major }\end{array}$ & $\begin{array}{c}33865 . \\
0\end{array}$ & 0.4733 & & \\
\hline $\begin{array}{l}\mathrm{S} 25 \\
\text { major }\end{array}$ & $\begin{array}{c}35273 . \\
4\end{array}$ & 0.2726 & & \\
\hline $\begin{array}{l}\mathrm{S} 25 \\
\text { major }\end{array}$ & $\begin{array}{c}35273 . \\
4\end{array}$ & 0.2726 & & \\
\hline
\end{tabular}




\section{Compound $[3]^{+3}$, triplet}

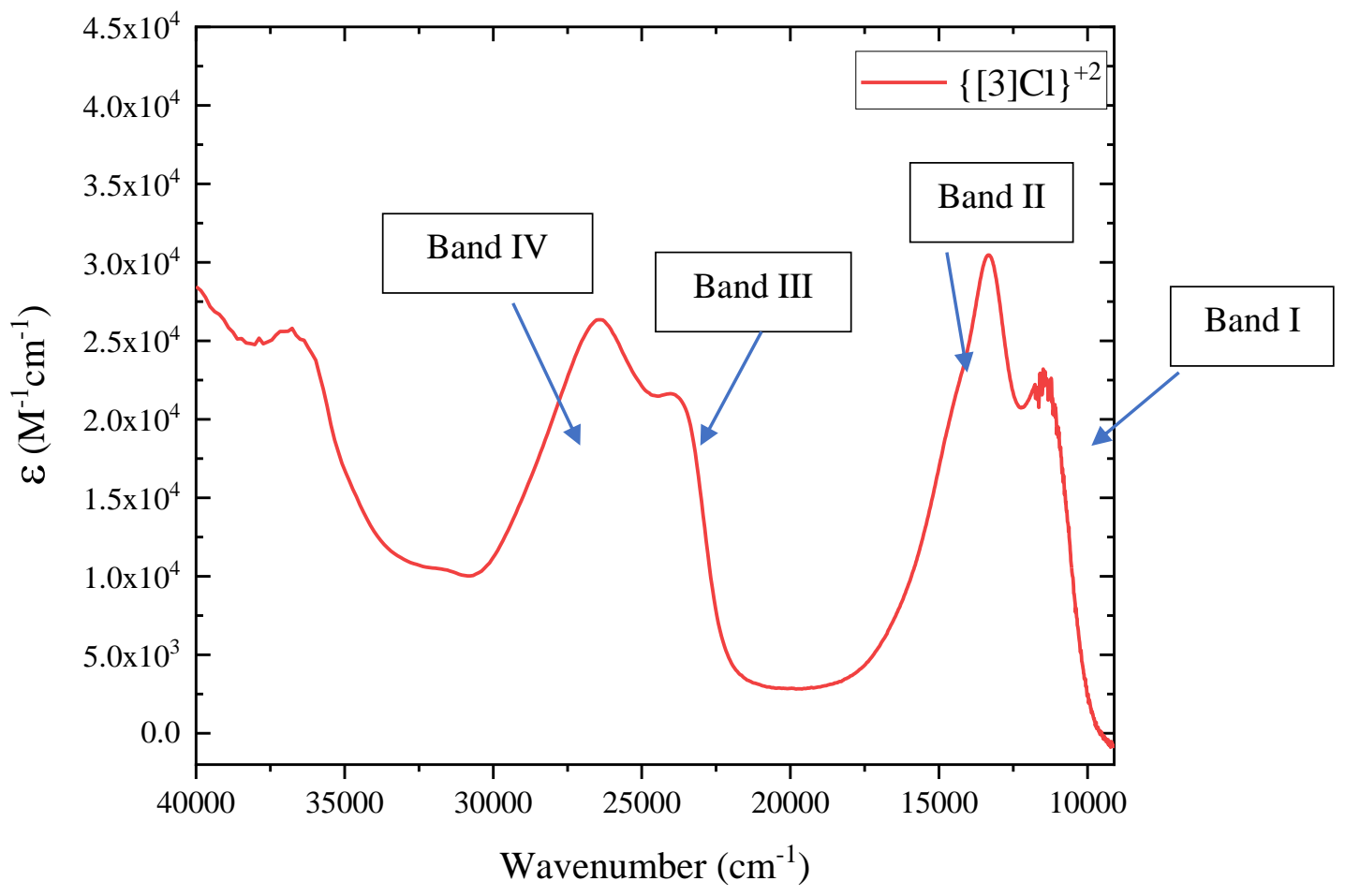

Figure S16. Experimental UV-Vis spectrum of $\{[3] \mathrm{Cl}\}^{+2}$ in $\mathrm{MeCN}$.

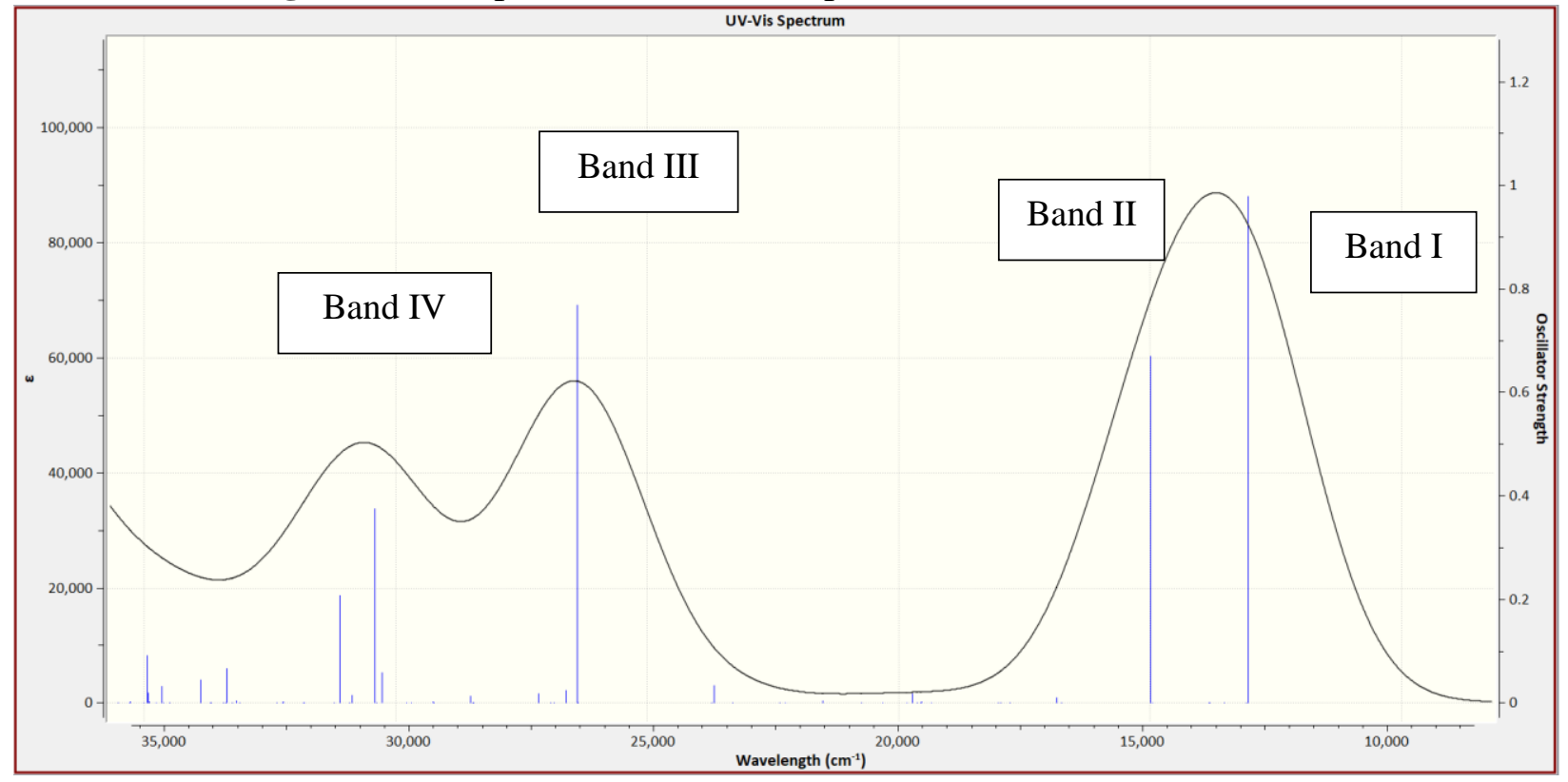

Figure S17. TD-DFT simulated UV-Vis spectrum of $[\mathbf{3}]^{+3}$

TD-DFT fails to predict the presence of a third, shoulder band at ca. $15000 \mathrm{~cm}^{-1}$. The region between $10000-20000 \mathrm{~cm}^{-1}$ is very similar to that of $[1]^{+2}$. The calculation also overestimates the energies associated with bands III and IV. However, it does succeed in predicting the absence of a significant absorption peak between $32000-35000 \mathrm{~cm}^{-1}$. 
Table S7. NTOs computed for the excited states of $[3]^{+3}$. Transitions are noted as NTO1 (hole) $\rightarrow$ NTO2 (electron). |isovalue $\mid=0.025$.

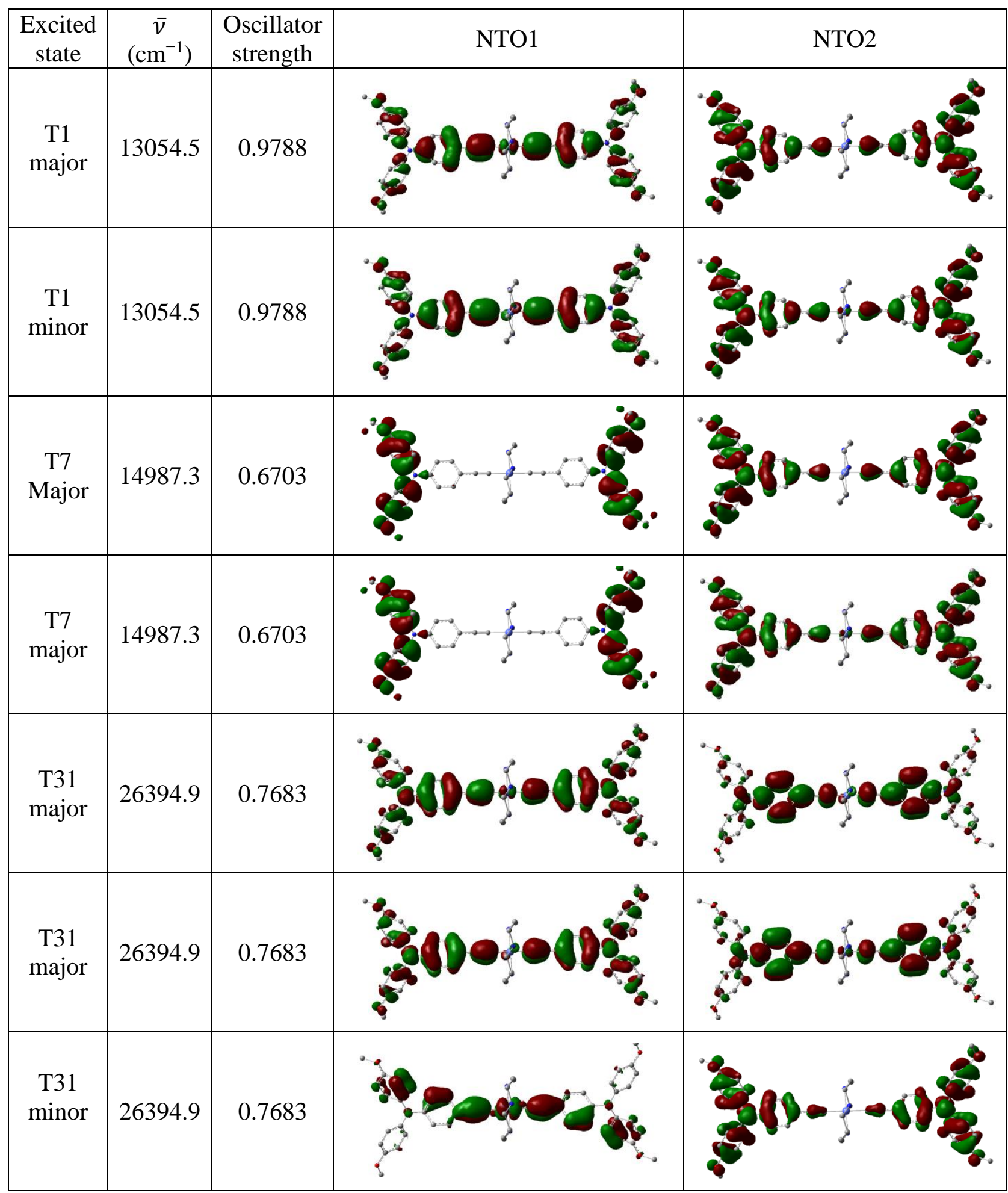




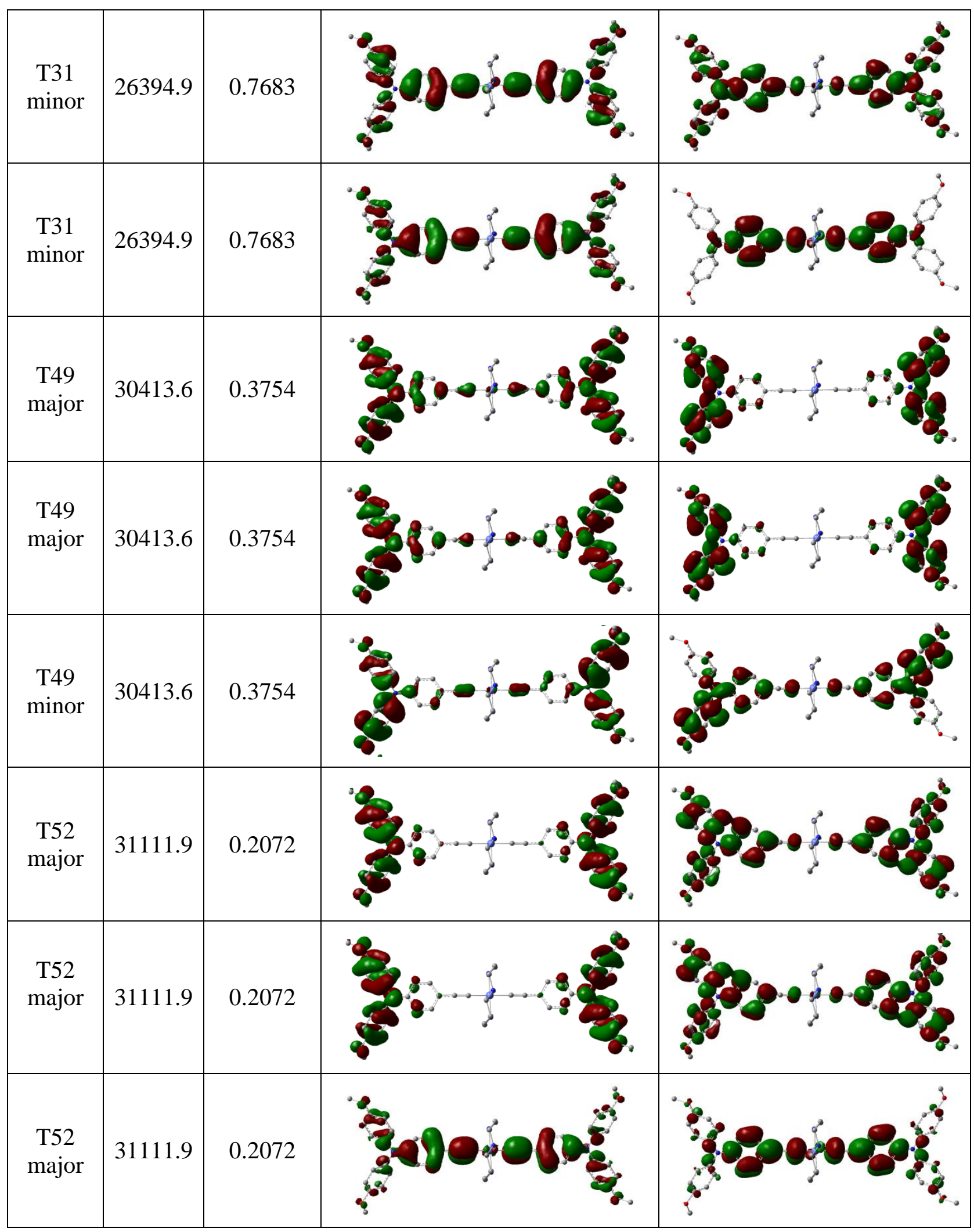




\begin{tabular}{|l|l|l|llll}
\hline $\begin{array}{c}\text { T52 } \\
\text { Minor }\end{array}$ & 31111.9 & 0.2072 & & \\
T52 \\
Minor
\end{tabular}

Table S8. Molecular orbital diagrams plotted at $\mid$ isovalue $\mid=0.025$ and corresponding orbital energies (in eV) for $\mathbf{2 a}$ from DFT.

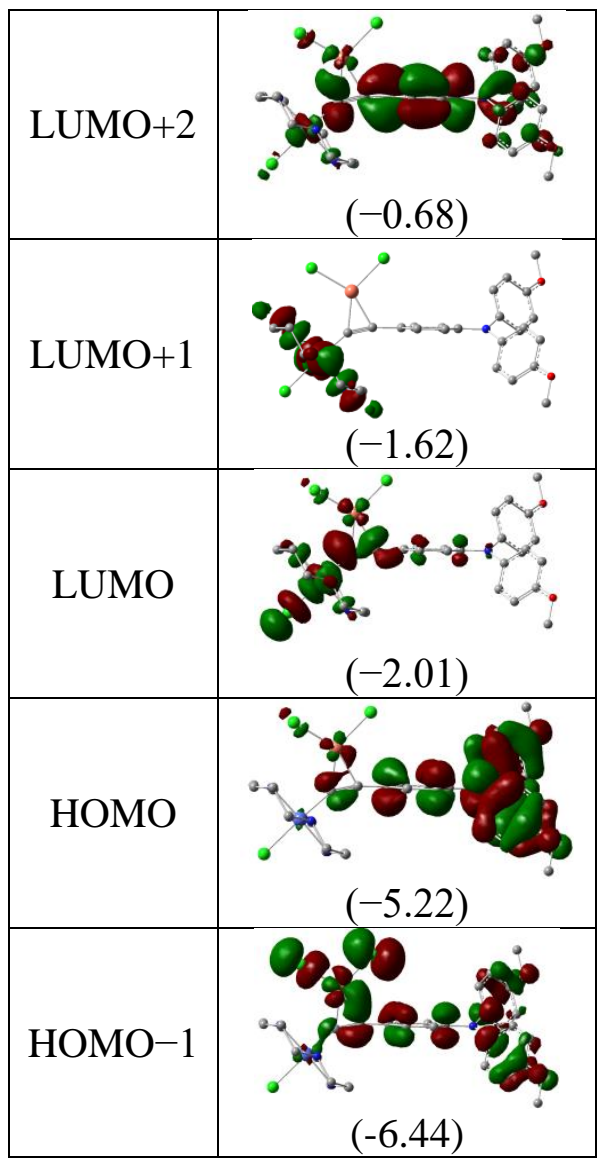




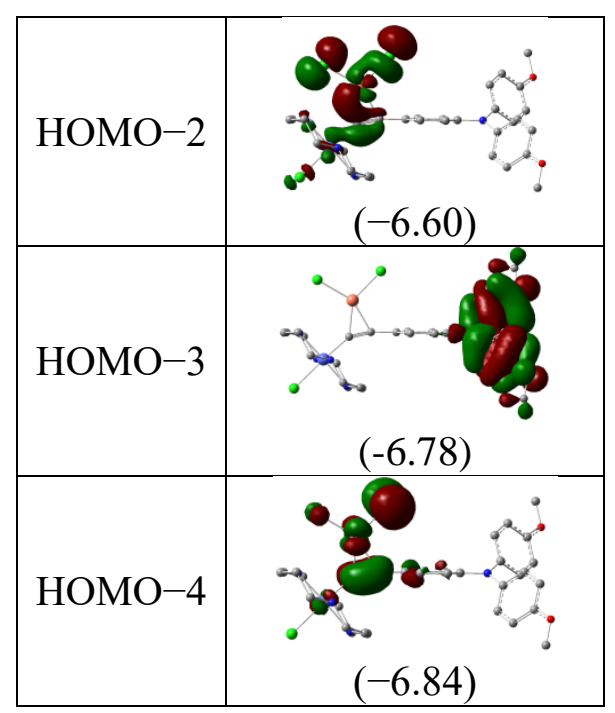

References:

(1) Sheldrick, G. M. A short history of SHELX. Acta Crystallogr A 2008, 64, 112-122.

(2) Gaussian 16 Rev. A.03; Frisch, M. J.; Trucks, G. W.; Schlegel, H. B.; Scuseria, G. E.; Robb, M. A.; Cheeseman, J. R.; Scalmani, G.; Barone, V.; Petersson, G. A.; Nakatsuji, H.; Li, X.; Caricato, M.; Marenich, A. V.; Bloino, J.; Janesko, B. G.; Gomperts, R.; Mennucci, B.; Hratchian, H. P.; Ortiz, J. V.; Izmaylov, A. F.; Sonnenberg, J. L.; Williams; Ding, F.; Lipparini, F.; Egidi, F.; Goings, J.; Peng, B.; Petrone, A.; Henderson, T.; Ranasinghe, D.; Zakrzewski, V. G.; Gao, J.; Rega, N.; Zheng, G.; Liang, W.; Hada, M.; Ehara, M.; Toyota, K.; Fukuda, R.; Hasegawa, J.; Ishida, M.; Nakajima, T.; Honda, Y.; Kitao, O.; Nakai, H.; Vreven, T.; Throssell, K.; Montgomery Jr., J. A.; Peralta, J. E.; Ogliaro, F.; Bearpark, M. J.; Heyd, J. J.; Brothers, E. N.; Kudin, K. N.; Staroverov, V. N.; Keith, T. A.; Kobayashi, R.; Normand, J.; Raghavachari, K.; Rendell, A. P.; Burant, J. C.; Iyengar, S. S.; Tomasi, J.; Cossi, M.; Millam, J. M.; Klene, M.; Adamo, C.; Cammi, R.; Ochterski, J. W.; Martin, R. L.; Morokuma, K.; Farkas, O.; Foresman, J. B.; Fox, D. J.: Wallingford, CT, 2016.

(3) Vosko, S. H.; Wilk, L.; Nusair, M. Accurate spin-dependent electron liquid correlation energies for local spin density calculations: a critical analysis. Can. J. Phys. 1980, 58, 1200-1211.

(4) Lee, C.; Yang, W.; Parr, R. G. Development of the Colle-Salvetti correlation-energy formula into a functional of the electron density. Phys. Rev. B 1988, 37, 785-789.

(5) Becke, A. D. Density-functional exchange-energy approximation with correct asymptotic behavior. Phys. Rev. A 1988, 38, 3098-3100.

(6) Stephens, P. J.; Devlin, F. J.; Chabalowski, C. F.; Frisch, M. J. Ab Initio calculation of vibrational absorption and circular dichroism spectra using density functional force fields. J. Phys. Chem. 1994, 98, 11623-11627.

(7) Yanai, T.; Tew, D. P.; Handy, N. C. A new hybrid exchange-correlation functional using the Coulomb-attenuating method (CAM-B3LYP). Chem. Phys. Lett. 2004, 393, 51-57.

(8) Zhao, Y.; Truhlar, D. G. The M06 suite of density functionals for main group thermochemistry, thermochemical kinetics, noncovalent interactions, excited states, and transition elements: Two new functionals and systematic testing of four M06-class functionals and 12 other function. Theor. Chem. Acc. 2008, 120, 215-241.

(9) Chai, J. D.; Head-Gordon, M. Systematic optimization of long-range corrected hybrid density functionals. J. Chem. Phys. 2008, 128, 084106. 
(10) Zhao, Y.; Truhlar, D. G. Density functional for spectroscopy: No long-range self-interaction error, good performance for Rydberg and charge-transfer states, and better performance on average than B3LYP for ground states. J. Phys. Chem. A 2006, 110, 13126-13130.

(11) Weigend, F.; Ahlrichs, R. Balanced basis sets of split valence, triple zeta valence and quadruple zeta valence quality for $\mathrm{H}$ to Rn: Design and assessment of accuracy. Phys. Chem. Chem. Phys. 2005, 7, 3297-3305.

(12) Francl, M. M.; Pietro, W. J.; Hehre, W. J.; Binkley, J. S.; Gordon, M. S.; DeFrees, D. J.; Pople, J. A. Self-consistent molecular orbital methods. XXIII. A polarization-type basis set for second-row elements. J. Chem. Phys. 1982, 77, 3654-3665.

(13) Hariharan, P. C.; Pople, J. A. The influence of polarization functions on molecular orbital hydrogenation energies. Theor. Chim. Acta 1973, 28, 213-222.

(14) Cossi, M.; Rega, N.; Scalmani, G.; Barone, V. Energies, structures, and electronic properties of molecules in solution with the C-PCM solvation model. J. Comput. Chem. 2003, 2, 669-681.

(15) Barone, V.; Cossi, M. Quantum calculation of molecular energies and energy gradients in solution by a conductor solvent model. J. Phys. Chem. A 1998, 102, 1995-2001.

(16) Grimme, S.; Antony, J.; Ehrlich, S.; Krieg, H. A consistent and accurate ab initio parametrization of density functional dispersion correction (DFT-D) for the 94 elements H-Pu. J. Chem. Phys. 2010, 132, 154104.

(17) Zhang, M. X.; Zhang, J.; Yin, J.; Hartl, F.; Liu, S. H. Anodic electrochemistry of mono- and dinuclear aminophenylferrocene and diphenylaminoferrocene complexes. Dalton Trans. 2018, 47, 61126123.

(18) Hirata, S.; Head-Gordon, M. Time-dependent density functional theory within the Tamm-Dancoff approximation. Chem. Phys. Lett. 1999, 314, 291-299.

(19) Martin, R. L. Natural Transition Orbitals. J. Chem. Phys. 2003, 118, 4775-4777. 